\title{
A human immune data-informed vaccine concept elicits strong and broad T-cell specificities associated with HIV-1 control in mice and macaques
}

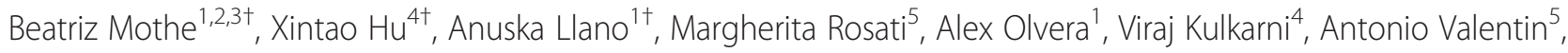
Candido Alicea ${ }^{4}$, Guy R Pilkington ${ }^{4}$, Niranjan Y Sardesai ${ }^{6}$, Muntsa Rocafort ${ }^{1}$, Manel Crespo ${ }^{7}$, Jorge Carrillo ${ }^{1}$, Andrés Marco ${ }^{8}$, James I Mullins ${ }^{9}$, Lucy Dorrell ${ }^{10}$, Tomáš Hanke ${ }^{11}$, Bonaventura Clotet ${ }^{1,2,3,12}$, George N Pavlakis ${ }^{5}$, Barbara K Felber ${ }^{4}$ and Christian Brander $1,3,12,13^{*}$

\begin{abstract}
Background: None of the HIV T-cell vaccine candidates that have reached advanced clinical testing have been able to induce protective $T$ cell immunity. A major reason for these failures may have been suboptimal $T$ cell immunogen designs.

Methods: To overcome this problem, we used a novel immunogen design approach that is based on functional T cell response data from more than 1,000 HIV-1 clade B and C infected individuals and which aims to direct the $T$ cell response to the most vulnerable sites of HIV-1.

Results: Our approach identified 16 regions in Gag, Pol, Vif and Nef that were relatively conserved and predominantly targeted by individuals with reduced viral loads. These regions formed the basis of the HIVACAT T-cell Immunogen (HTI) sequence which is 529 amino acids in length, includes more than 50 optimally defined $C D 4^{+}$and $C D 8^{+}$T-cell epitopes restricted by a wide range of HLA class I and II molecules and covers viral sites where mutations led to a dramatic reduction in viral replicative fitness. In both, C57BL/6 mice and Indian rhesus macaques immunized with an HTI-expressing DNA plasmid (DNA.HTI) induced broad and balanced T-cell responses to several segments within Gag, Pol, and Vif. DNA.HTI induced robust CD4 ${ }^{+}$and $C D 8^{+} T$ cell responses that were increased by a booster vaccination using modified virus Ankara (MVA.HTI), expanding the DNA.HTI induced response to up to 3.2\% IFN- $\gamma$ T-cells in macaques. HTI-specific T cells showed a central and effector memory phenotype with a significant fraction of the IFN- $\gamma^{+} \mathrm{CD}^{+}$T cells being Granzyme $\mathrm{B}^{+}$and able to degranulate $\left(\mathrm{CD} 107 \mathrm{a}^{+}\right)$.

Conclusions: These data demonstrate the immunogenicity of a novel HIV-1 T cell vaccine concept that induced broadly balanced responses to vulnerable sites of HIV-1 while avoiding the induction of responses to potential decoy targets that may divert effective T-cell responses towards variable and less protective viral determinants.
\end{abstract}

Keywords: HIV-1 T-cell immunogen, HIV-1 specific CTL, HLA, Immunogenicity, Subdominant, Viral fitness, CTL escape, T-helper epitope, Population coverage

\footnotetext{
* Correspondence: cbrander@irsicaixa.es

${ }^{\dagger}$ Equal contributors

'IrsiCaixa AIDS Research Institute - HIVACAT, Hospital Germans Trias i Pujol,

Crta Canyet s/n., 08916 Badalona, Barcelona, Spain

${ }^{3}$ Universitat de Vic-Universitat Central de Catalunya (UVic-UCC), Vic, Spain

Full list of author information is available at the end of the article
} 


\section{Background}

HIV-1 infection induces strong and broadly directed HLA class I and class II restricted T-cell responses, for which some specific epitopes and restricting HLA alleles have been associated with relative in vivo virus control or lack thereof [1-3]. Among these, $\mathrm{CD}^{+}$cytotoxic $\mathrm{T}$ lymphocytes (CTL) responses to HIV-1 Gag have most consistently been associated with reduced viral loads in both HIV-1 clade B- and C-infected cohorts [2,4]. This is in line with data from post-hoc analyses of the STEP vaccine trial, where individuals in whom vaccine-induced responses targeted $\geq 3$ different Gag epitopes achieved a lower viral load than subjects without Gag responses [5]. $\mathrm{CD}^{+}{ }^{+} \mathrm{T}$-cell responses to Gag have also been associated with relative HIV-1 control [6,7]. However, it remains unclear whether the relative benefit of Gag is due to high protein expression levels, rapid representation of viral particle-derived CTL epitopes [8], reduced susceptibility of Gag-specific CTL to Nef-mediated immune evasion strategies [9] or particular amino acid composition and inherently greater immunogenicity [10]. In addition, the elevated level of conservation of Gag across viral isolates [11] and the severe fitness reductions caused by CTL escape variants [12-16] may provide Gag-specific T-cell responses with a particular advantage. At the same time, it is also clear that not all Gag-specific responses exert the same antiviral activity, suggesting that a rational selection of Gag components could help focus vaccine induced responses onto the most protective targets. The same likely applies for all other viral proteins as well, as they may contain some regions that are of particular value for inclusion in a vaccine while other regions or proteins may induce less useful $\mathrm{T}$ cell responses. As such, effective vaccine design should probably aim to induce broad and evenly distributed responses to conserved and vulnerable sites of the virus while avoiding the induction of responses to regions that can be highly immunogenic but that may act as potential "decoy" targets and divert responses away from more relevant targets [17-22].

The failure of various T-cell vaccine candidates expressing entire HIV-1 proteins in large human clinical trials and data from post-trial analyses suggesting a sieve effect on the infecting viral strains, indicate the urgent need to improve vaccine immunogen design [23-26]. Here, we describe a rational design and pre-clinical testing of a novel approach to HIV-1 T cell immunogen development and its implication for HIV-1 control. Starting with a comprehensive screening of large cohorts of clade B and C HIV-1-infected individuals, we identified viral targets associated with relative HIV-1 control [27,28]. These earlier analyses in aggregate identified 26 regions in HIV-1 Gag, Pol, Vif and Nef proteins that (i) were preferentially targeted by individuals with low viral loads and largely independent on beneficial HLA class I genotypes, (ii) turned out to be more conserved than the rest of the proteome, and (iii) elicited responses of higher functional avidity and broader variant cross-reactivity than responses to other regions. These identified regions provided the basis for a polypeptide sequence that is designed to a) contain epitope-rich regions in the context of a broad HLA class I and class II allele coverage, b) induce responses to subdominant epitopes associated with viral control and c) focus the vaccine-induced response onto the most vulnerable targets in the viral proteome. The conserved elements (CE) immunogen designs, although modified using immune response and virologic control data, was driven first by sequence conservation [17-19]. The rational design of this novel HTI sequence also differs conceptually from other approaches that have either been based on full protein sequences [23-25], on very short, conserved segments of the virus [29,30] select conserved CD8 T cell epitopes [31] or other approaches that attempt to cover viral diversity [32-35] and which did not incorporate human immune reactivity data as the base of their designs. The immune responses observed in preclinical testing in C57BL/6 mice and Indian rhesus macaques show the expected broadly directed responses and warrant further development in human clinical trials.

\section{Methods}

\section{HIV-1 infected patients and human PBMC samples for ELISPOT analyses}

Chronically HIV-1 infected individuals not receiving antiretroviral treatment that fulfilled the following criteria were recruited from the HIV Unit in Hospital Germans Trias i Pujol, Badalona and Hospital de la Vall d'Hebron, Barcelona, Spain: chronic HIV-1 infection with (i) persistent undetectable viral loads (Elite controllers, $\mathrm{n}=38$ ), (ii) stable plasma HIV-1 RNA levels $<2,000$ copies $/ \mathrm{ml}$ (Viremic controllers, $\mathrm{n}=27$ ), and (iii) non-controlled viral replication with current plasma HIV-1 RNA levels $>50,000$ copies $/ \mathrm{ml}$ (Non-controllers, $\mathrm{n}=30$ ) (Table 1 ). The study was approved by the Institutional Review Board of both participating hospitals, and all individuals provided written informed consent before entering the study. HLA genotypes were heterogeneous in all groups (data not shown). PBMC were processed within $4 \mathrm{~h}$ after venepuncture and cells stored at liquid nitrogen until use. A set of 410 overlapping-peptides (18-mers OLPs) was used to screen for HIV-specific T-cell responses to the full HIV-1 proteome. The peptides spanned all HIV-1 proteins and were used in a matrix layout of 6-12 peptides per pool for comprehensive screening as previously described [36]. All positive wells in the matrix screen were confirmed the following day on a single-peptide level. Results are presented as the contribution of responses targeting 
Table 1 Clinical data of cohort for human PBMC samples ${ }^{a}$ and HLA class I allele distribution

\begin{tabular}{llll}
\hline Group (N) & HIV-1 RNA levels (copies/ml) & CD4 ${ }^{+}$T cells (cells/mm $\left.\mathbf{m m}^{\mathbf{3}}\right)$ & Protective HLA alleles \\
\hline EC (38) & UD $^{b}$ & $826(606 ; 946)$ & $B^{*} 27(8 \%) B^{*} 57(26 \%) B^{*} 58(3 \%)$ \\
VC (27) & $540(265 ; 1,182)$ & $642(498 ; 1,014)$ & $B^{*} 27(4 \%) B^{*} 57(18 \%) B^{*} 58(7 \%)$ \\
NC (30) & $140,00(58,000 ; 415,000)$ & $128(59 ; 211)$ & $B^{*} 27(7 \%) B^{*} 57(7 \%) B^{*} 58(7 \%)$ \\
\hline
\end{tabular}

Values expressed as median (IQR).

${ }^{\mathrm{b}} \mathrm{UD}$, undetectable viremia (<49 copies/ml).

OLPs included in the HTI sequence relative to the total response to the full HIV-1 proteome.

\section{DNA.HTI and MVA.HTI vaccines}

The HTI plasmid DNA (plasmid 298H) contains the expression-optimized [37-39] HTI open reading frame inserted into a pCMVkan vector comprising a plasmid backbone optimized for growth in bacteria, the human cytomegalovirus (CMV) promoter without any introns, the optimized HTI gene, the bovine growth hormone (BGH) polyadenylation site, and the kanamycin resistance gene. The HTI gene contains the human GM-CSF signal peptide (AA 1-17; Genbank accession Nr. NP_000749) at the N terminus as a means to enhance translocation into the Endoplasmatic Reticulum [40]. A FLAG-tag was added at the C-terminus (HTI-FLAG) for expression analysis in transfected HEK293 cells. RNA/codon optimized clade B (strain HXB2) genes for full-length p55 $5^{\text {gag }}$ (plasmid 114H), Pol (plasmid 133H), NefTatVif fusion (NTV, plasmid $132 \mathrm{H}$ ), and LAMP-Pol (plasmids 128H) and LAMP-NTV (plasmids 129H), fusion proteins with the lysosomal associated membrane protein 1 (LAMP-1) [40] were used. The IL-12 DNA (plasmid AG157) produces the expressionoptimized rhesus macaque IL-12 cytokine [41]. Plasmid DNAs were produced in E.coli DH10B (Invitrogen), and the purified endotoxin-free DNAs (Qiagen) were resuspended in sterile water (Gibco).

A recombinant MVA expressing the HTI gene was generated as described previously $[42,43]$. Briefly, chicken embryo fibroblast (CEF) cells grown in Dulbeco's Modified Eagle's Medium supplemented with 10\% FBS, penicillin/ streptomycin and glutamine (DMEM 10) were infected with parental MVA and transfected using Superfectin (Qiagen) with DNA.HTI. These cells were MoFlo singlecell sorted into 96-well plates and these were used to culture recombinant virus upon addition of fresh CEF. Those wells containing suitably infected cells were harvested and screened by PCR to confirm identity and test purity. Plaque picking was performed using CEF until the culture was free of parental virus, as determined by PCR, after which a master virus stock was grown, purified on a $36 \%$ sucrose cushion, titered and stored at $-80^{\circ} \mathrm{C}$ until use.

\section{HTI DNA expression upon transient transfection}

Briefly, $1 \times 10^{6}$ human HEK 293 cells grown in complete DMEM plus $10 \%$ fetal bovine serum (FBS) were plated on to $60-\mathrm{mm}$ tissue culture dishes and allowed to adhere overnight. Cells were transfected by CaPhosphate DNA co-precipitation with a total of $7 \mu \mathrm{g}$ of DNA (100 ng or $250 \mathrm{ng}$ of the plasmid DNA adjusted to $7 \mu \mathrm{g}$ with Bluescript DNA). Six hours after transfection the medium was replaced with $3 \mathrm{ml}$ of DMEM supplemented with $2 \%$ of FBS. After 24 and $48 \mathrm{hrs}$ the cells and the supernatants were collected in 0.5X RIPA (Boston BioProducts, Ashland, MA). Protein expression was analyzed by Western immunoblots using $10 \%$ or $12 \%$ sodium dodecyl sulfate polyacrylamide gels (Nu-Page Bis-Tris, NuPAGE, Invitrogen, Life Technologies Corp., Carlsbad, CA) and blotted onto nitrocellulose membranes which were probed with a anti-FLAG-HRP antibody (dilution 1:4000, Sigma) or a goat anti-p24 ${ }^{\text {gag }}$ antibody (dilution 1:3000, provided by L. Arthur, SAIC, NCI, Frederick) followed by anti-goat IgG-HRP labeled antibody (dilution 1:10,000; Calbiochem, EMD chemicals, Gibbstown, NJ). As control, the membranes were probed with anti-human pan-actin antibody (clone C4, EMD Millipore, Billerica, MA) at a dilution of 1:10,000. The bands were visualized using the enhanced chemiluminescence (ECL) plus Western blotting detection system (GE HealthCare, Piscataway, NJ). HeLa-derived HLtat cells were plated with $2 \times 10^{5}$ cells/35-mm glass-bottomed plate and 24 hrs later were transfected with $500 \mathrm{ng}$ of the DNA.HTI-FLAG plasmid. The next day, the cells were fixed with $4 \%$ paraformaldehyde in PBS, permeabilized with $0.5 \%$ Triton X-100 in PBS and incubated with mouse anti-FLAG antibody (Sigma) at 1:1,000 dilution, followed by incubation with anti-mouse Alexa-fluor 488 and DAPI at 1:1000 dilution. The cells were visualized on a Zeiss Observer Z1 fluorescent microscope using Zeiss Axiovision software (Carl Zeiss Microimaging, GmbH, Göttingen, Germany).

\section{Vaccination of C57BL/6 mice}

Groups of five female C57BL/6 (6 to 8 weeks old) were obtained from Charles River Laboratories, Inc. (Frederick, $\mathrm{MD}$ ) and were housed at the National Cancer Institute, Frederick, MD, in a temperature-controlled, light-cycled facility. The mice were immunized with DNA.HTI or DNA.COMB consisting of gag, pol and NTV (nef, tat, vif) expression plasmids using doses of $20 \mu \mathrm{g}$ DNA per mouse. The DNA was delivered by intramuscular injection followed by in vivo electroporation by ELGEN ${ }^{\circ}$ constant current electroporation device (Inovio Pharmaceuticals, 
Inc, Blue Bell, PA). DNA.COMB consists of DNA.Gag clade B (expressing complete clade B p55 Gag protein) in combination with DNA.Pol (expresses full-length Pol protein) and DNA.NTV (expressing a chimeric protein of Nef, Tat and Vif) plasmids. The animals were vaccinated twice ( 0 and 3 weeks or 0 and 4 weeks), and were sacrificed 2 weeks after the last vaccination when spleens and blood were collected for the analysis of cellular and humoral responses.

For heterologous prime/boost experiments, groups of 6 C57BL/6 mice (Harlan Laboratories Ltd., Barcelona, Spain) were used in the Hospital Germans Trias i Pujol Animal facility. Mice were primed intramuscularly with $100 \mu \mathrm{g}$ of DNA.HTI (2, 3 or 4 vaccinations) followed by a $10^{6} \mathrm{pfu}$ of MVA.HTI boost, as indicated. All vaccinations were separated by three weeks. All mice were sacrificed two weeks after the last vaccination when splenocytes and serum were harvested for immunogenicity studies. Spleens were removed and pressed individually through a cell strainer (Falcon) using a 5-ml syringe rubber plunger. Following red blood cell lysis, splenocytes were washed and resuspended in RPMI 1640 supplemented with 10\% FCS, penicillin/streptomycin (R10) and frozen until use.

\section{Overlapping peptides and distribution of peptide pools}

To allow for comparisons in immunogenicity among groups of animals, sequences of the immunogenic segments contained in HTI were confirmed to be $>95 \%$ matched with the sequences from the full-length proteins expressed by control DNAs. Ex vivo immune analyses of murine experiments in which DNA expressing full proteins were used, employed a previously described overlapping peptide set (410 18-mers OLP) spanning the entire viral proteome [36]. Peptides were 18-mers varying from 15-20 amino acids in length and overlapping by 10 amino acids, designed using the PeptGen algorithm at the Los Alamos HIV database [44] and based on the 2001 consensus- $B$ sequence $[2,36]$. To assess responses to entire Gag, Pol, Nef, Tat and Vif and the relative distribution of responses to regions covered by HTI T-cell immunogen, a set of peptide pools was designed that consisted of 6 pools for Gag (11 peptides/ each), 8 for Pol (16 or 17 peptides/each), 2 for Nef (13 and 14 peptides/each), 1 for Tat (12 peptides) and 2 for Vif (12 peptides/each) proteins. A second peptide set consisting of 8 peptide pools covered the protein subunits spanning the 16 segments included in the HTI and was used in the experiments where electroporation was performed. For experiments that assessed the immune responses after heterologous prime/boost vaccinations and for analyses that measured the potential immunogenicity of junctional epitopes an overlapping peptide set of 147 peptides of 15 amino acids in length (overlapping by 11 residues) spanning the entire HTI (including the leader sequence and linkers regions) was synthesized. For mice experiments, HTI peptides were pooled into 18 different pools, according to protein subunits and considering a similar number of peptides per pool ( 1 pool for the signal peptide sequence, $n=4$ peptides; 7 pools for Gag, $\mathrm{n}=8-11$ peptides/each; 7 pools for Pol, $\mathrm{n}=5-11$ peptides/each; 2 pools for Vif, $\mathrm{n}=6-8$ peptides/each and 1 pool for Nef, $\mathrm{n}=2$ peptides). In macaque experiments and to assess breadth of vaccine induced responses, peptides were pooled and distributed covering each HTI segment individually (S1-S16).

\section{Murine IFN- $\gamma$ ELISPOT assay}

ELISPOT assay was performed by using a mouse IFN- $\gamma$ ELISPOT kit (ALP) (Mabtech AB, Stockholm, SE) following the manufacturer's instructions with minor modifications. For all assays, frozen splenocytes were thawed and rested for $5 \mathrm{hrs}$ at $37^{\circ} \mathrm{C}$ in $\mathrm{R} 10$ medium before use. Cells were added at an input cell number of $4 \times 10^{5}$ cells/well in $140 \mu \mathrm{l}$ of R10 in 96-well polyvinylidene plates (Millipore Corp., Bedford, MA) alone or with HIV-1- specific peptide pools $(14 \mu \mathrm{g} / \mathrm{ml}$ final concentration for each peptide) for $16 \mathrm{hrs}$ at $37^{\circ} \mathrm{C}$ in $5 \% \mathrm{CO}_{2}$. Concanavalin A (Sigma-Aldrich Corp., Saint Louis, $\mathrm{MO}$ ), at $5 \mathrm{mg} / \mathrm{ml}$, was used as a positive control. The plates were developed with one-step 5-bromo-4-chloro3-indolyl phosphate/Nitroblue Tetrazolium (BCIP/NBT, Bio-Rad Laboratories, Inc., Irvine, $\mathrm{CA}$ ). The spots on the plates were counted using an automated ELISPOT reader system (CTL Analyzers LLC, Cleveland, $\mathrm{OH}$ ) using ImmunoSpot software and the magnitude of responses was expressed as spot forming cells (SFC) per million splenocytes. The threshold for positive responses was defined as at least 5 spots per well and responses exceeding the mean number of spots in negative control wells plus 3 standard deviations of the negative control wells and three times the mean of negative control wells, whichever was higher.

\section{Humoral immune response analysis}

Humoral responses were analyzed in pooled mice plasma. Binding antibodies to HIV-1 Gag were detected by Western immunoblot using cell extracts from HEK293 cells transfected with $1 \mu \mathrm{g}$ of Gag and Gag-Pol expression vectors, separated on $12 \%$ SDS-PAGE, and the membranes were probed with pooled plasma (at a 1:100 dilution) and the bands were visualized by anti-mouse IgG-HRP antibody (1:10,000 dilution, GE Healthcare, Piscataway, NJ). Serial dilutions of plasma samples were analyzed by standard HIV-1 clade B p24 ${ }^{\text {gag }}$ ELISA (Advanced Bioscience Lab, Rockville, MD), measuring optical absorbance at $450 \mathrm{~nm}$. 


\section{Vaccination of rhesus macaques}

Indian rhesus macaques (R678, R679, R680, R681) were vaccinated with $2 \mathrm{mg}$ of DNA.HTI together with $0.2 \mu \mathrm{g}$ of macaque IL-12 DNA formulated in $0.6 \mathrm{ml}$ of sterile water (Hospira, Inc., Lake Forest, IL). DNAs were delivered via intramuscular (IM) injection at two different sites $(0.3 \mathrm{ml}$ each site) followed by in vivo electroporation using the Elgen 1000 device (Inovio, Pharmaceuticals, Inc, Blue Bell, PA). The animals received three vaccinations with DNA.HTI at 0,1 and 3 month. After a rest period of 4.5 months, the animals received a boost with recombinant MVA.HTI $\left(10^{8} \mathrm{pfu} /\right.$ dose $)$ delivered via the IM route as a single inoculation. A 2nd MVA.HTI boost was administered 3 months later. All macaques used in this study were males and were 3 years of age at the onset of the study. Vaccinations were performed under anesthesia (Ketamine administered at $10 \mathrm{mg} / \mathrm{kg}$ ) and all efforts were made to minimize suffering. No adverse effects were found. None of the animals were euthanized as part of this study.

\section{Intracellular cytokine staining of macaque PBMC}

Macaque PBMC were isolated by Ficoll-hypaque (Histopaque, Sigma, St. Louis, MO) centrifugation, and cultured in 96well plates as described previously [45]. PBMC were stimulated overnight with peptide pools (final concentration of $1 \mu \mathrm{g} / \mathrm{ml}$ for each peptide) in the presence of monensin (BD Pharmingen, San Diego, CA), Antigen-specific T cells were monitored by intracellular cytokine staining followed by polychromatic flow cytometry. The cells were stained with the following cocktail of cell surface antibodies: CD3-APCCy7 (clone SP34-2), CD4-V500 (clone L200), CD95-FITC (clone DX2) (BD Pharmingen), CD8-Alexa Fluor-405 (clone 3B5, Invitrogen, Carlsbad, CA), CD28PerCP Cy5.5 (clone CD28.2, BioLegend, San Diego, CA). CD107a-eFluor 660 (clone eBioH4A3, eBioscience San Diego, CA) antibody was added to the cells $10 \mathrm{~min}$ after addition of the peptides. After cell permeabilization with Cytofix/Cytoperm (BD Biosciences), intracellular staining was performed using IFN- $\gamma-\mathrm{PE} \mathrm{Cy} 7$ (clone B27, $\mathrm{BD}$ Pharmingen) and Granzyme B-PE antibodies (clone GB12, Invitrogen). In all experiments, PBMC cultured in medium without peptide pools or stimulated with phorbol myristate acetate (PMA) and calcium ionophore (Sigma, St. Louis, MO) were used as negative and positive control, respectively. Samples were considered positive, if the frequency of the IFN- $\gamma^{+} \mathrm{T}$ cells of the peptide stimulated sample was more than 2 fold higher than the frequency obtained in unstimulated (without peptide) medium only control sample. At least $10^{5} \mathrm{~T}$ cells from each sample were acquired on an LSR II flow cytometer (BD Biosciences, San Jose, CA) and the data were analyzed using FlowJo software (Tree Star, Inc., Ashland, OR). Subsets of antigenspecific $\mathrm{T}$ cells were defined by Boolean gating, including central memory $\left(\mathrm{CD} 95^{+} \mathrm{CD} 28^{+}\right)$, effector memory $\left(\mathrm{CD} 95^{+}\right.$ $\mathrm{CD} 28^{-}$) and cytotoxic potential (granzyme B and CD107a expression).

\section{Humoral immune responses of vaccinated macaques} HEK293 cells were transfected with $0.5 \mu \mathrm{g}$ of HTIFLAG expression vector and immunoprecipitated using anti-Flag M2 affinity gel (Sigma, Catalog Number A2220) to concentrate the protein 20 -fold. The proteins were separated on $12 \%$ SDS-PAGE and transferred to membrane as described above. The membranes were probed with plasma from the vaccinated macaques at a 1:100 dilution, and the bands were visualized using a 1:10,000 dilution of an anti-monkey IgG+, IgA+, IgM +-HRPconjugated antibody (cat\# 43R-IG050hrp; Fitzgerald Industries International Inc., MA). The bands were visualized using the enhanced chemiluminescence (ECL) plus Western blotting detection system (GE HealthCare, Piscataway, NJ). ELISA was performed using serial 4fold dilutions of plasma samples analyzed by standard HIV-1 clade B p24 gag ELISA (Advanced Bioscience Laboratory, Rockville, MD), measuring optical absorbance at $450 \mathrm{~nm}$.

\section{Statistical analyses}

The results are given as medians and interquartile range as indicated unless otherwise stated. GraphPad Prism version 4.0 for Windows (San Diego, CA) was used to compare response rates in both groups and subgroup analyses. Mann-Whitney test and Wilcoxon matched paired test were used for unpaired and paired comparisons, respectively.

\section{Ethics statement}

Chronically HIV-1 infected adult individuals were recruited from the HIV Unit in Hospital Germans Trias i Pujol, Badalona and Hospital de la Vall d'Hebron, Barcelona, Spain through the prospective observational cohort study named 'Controllers'. The study was approved by the Institutional Review Board of Hospital Germans Trias i Pujol, Badalona and Hospital de la Vall d'Hebron, Barcelona. All adult subjects provided written informed consent before entering the study.

C57BL/6 mice used for this study were cared at the temperature-controlled, light-cycled animal facilities of National Cancer Institute, Frederick, US and Hospital Germans Trias i Pujol, Badalona, Spain. The animal user protocol was approved by the NCI-Frederick Animal Care and Use Committee (AWA\#:A4159-01). Frederick National Laboratory for Cancer Research is accredited by AAALAC International and follows the Public Health Service Policy for the Care and Use of Laboratory Animals. Procedures involving mice performed at the animal facility of Hospital Germans Trias i Pujol followed EU normative 
on animal experimentation and were approved by the Animal Experimentation Ethical Committee from the Institut d'Investigació Sanitària Germans Trias i Pujol and the Department d'Agricultura, Ramaderia, Alimentació i Medi Natural of the Generalitat de Catalunya (DAAM order number 6390).

Indian rhesus macaques (Macaca mulatta) used in this study were housed at the Bioqual (formerly Advanced BioScience Laboratories, Inc.) animal facility. All animals were cared for and procedures performed under a protocol approved by the ABL Animal Care and Use Committee (animal welfare assurance no. A3467-01; protocol no. AUP572) and USDA Certificate number 51-R-0059. The macaques were managed according to the animal husbandry program, which aims at providing consistent and excellent care to nonhuman primates at the vivarium. This program operates based on the laws, regulations, and guidelines promulgated by the United States Department of Agriculture (e.g., the Animal Welfare Act and its regulations, and the Animal Care Policy Manual), Institute for Laboratory Animal Research (e.g., Guide for the Care and Use of Laboratory Animals, 8th edition), Public Health Service, National Research Council, Centers for Disease Control, and the Association for Assessment and Accreditation of Laboratory Animal Care (AAALAC) International. The nutritional plan utilized by the Animal Facility consisted of twice daily feeding of Labdiet 5045 High Protein Primate Diet and food intake was closely monitored by animal research technicians. This diet was also supplemented with a variety of fruits, vegetables, and other edible objects as part of the environmental enrichment program established by the Veterinary staff and enrichment Technician. Pairing of animals as part of the environmental enrichment program was managed by the enrichment technician. All primary enclosures and animal rooms were cleaned daily with water and sanitized at least once every two weeks. All macaques $(\mathrm{N}=4)$ used in this study were males and were 3 years of age at the onset of the study. Vaccinations were performed under anesthesia (Ketamine administered at $10 \mathrm{mg} / \mathrm{kg}$ ) and all efforts were made to minimize suffering. No adverse effects were found. None of the animals were euthanized as part of this study.

\section{Results and discussion}

Design of the HIVACAT T-cell immunogen (HTI) covering targets of effective antiviral $\mathrm{T}$ cell responses

We recently reported a systematic analysis of a large set of human immune data from cohorts of HIV-1 infected individuals $[27,28,36]$. In these analyses, more than 1,000 untreated HIV-1 clade B and clade C infected individuals were screened for anti-HIV $\mathrm{T}$ cell responses and regions of the viral proteome predominantly targeted by subjects with superior HIV-1 control were revealed. Of the 410 18-mer overlapping peptides (OLP) spanning the entire viral proteome, 26 consensus clade B derived OLP were identified for which the median viral load in the OLP responder group was significantly lower than the viral load in subjects who did not target these OLP (i.e., OLP nonresponders). These beneficial OLP were located in the HIV-1 Gag $(n=10)$, Pol $(n=12)$, Vif $(n=3)$ and Nef $(n=1)$ proteins (Table 2) and overlapped or closely matched the beneficial regions identified by analogous screening in HIV-1 clade C-infected subjects [28].

The 26 beneficial OLP were aligned and if located in close proximity $(<4$ amino acid residues between one end and the start of an adjacent beneficial OLP) fused using the naturally occurring clade $\mathrm{B}$ consensus sequence residues. This resulted in 16 continuous segments with the precise start and end positions defined after considering additional residues up- and down-stream of the identified 26 OLP for inclusion. These extensions and truncations

Table 2 List of identified beneficial overlapping peptides $(O L P, P R>1)$ incorporated in the final T-cell immunogen design, based on previous analysis [28]

\begin{tabular}{|c|c|c|c|}
\hline OLP no. & Protein & Subunit & OLP clade B cons sequence \\
\hline 3 & Gag & $\mathrm{p} 17$ & EKIRLRPGGKKKYKLKHI \\
\hline 6 & Gag & $\mathrm{p} 17$ & ASRELERFAVNPGLL \\
\hline 7 & Gag & $\mathrm{p} 17$ & ERFAVNPGLLETSEGCR \\
\hline 10 & Gag & $\mathrm{p} 17$ & QLQPSLQTGSEELRSLY \\
\hline 12 & Gag & $\mathrm{p} 17$ & SLYNTVATLYCVHQRIEV \\
\hline 23 & Gag & p24 & AFSPEVIPMFSALSEGA \\
\hline 31 & Gag & p24 & IAPGQMREPRGSDIA \\
\hline 34 & Gag & p24 & STLQEQIGWMTNNPPIPV \\
\hline 48 & Gag & p24 & ACQGVGGPGHKARVLAEA \\
\hline 60 & Gag & p15 & GKIWPSHKGRPGNFLQSR \\
\hline 75 & Nef & - & WLEAQEEEEVGFPVRPQV \\
\hline 159 & Pol & Prt & KMIGGIGGFIKVRQYDQI \\
\hline 160 & Pol & Prt & FIKVRQYDQILIEICGHK \\
\hline 161 & Pol & Prt & QILIEICGHKAIGTVLV \\
\hline 163 & Pol & Prt & LVGPTPVNIIGRNLLTQI \\
\hline 171 & Pol & RT & LVEICTEMEKEGKISKI \\
\hline 195 & Pol & RT & LRWGFTTPDKKHQKEPPF \\
\hline 196 & Pol & RT & DKKHQKEPPFLWMGYELH \\
\hline 210 & Pol & RT & EIQKQGQGQWTYQIY \\
\hline 269 & Pol & Int & TKELQKQITKIQNFRVYY \\
\hline 270 & Pol & Int & TKIQNFRVYYRDSRDPLW \\
\hline 271 & Pol & Int & YYRDSRDPLWKGPAKLLW \\
\hline 276 & Pol & Int & KIIRDYGKQMAGDDCVA \\
\hline 405 & Vif & - & VKHHMYISGKAKGWFYRH \\
\hline 406 & Vif & - & GKAKGWFYRHHYESTHPR \\
\hline 424 & Vif & - & TKLTEDRWNKPQKTKGHR \\
\hline
\end{tabular}


reflected: (i) extension of the segments beyond the OLP border so that additional specific epitopes that were considered important or can be presented as extended length variants were fully covered $[2,3,27,46]$ (ii) shortening of segments to exclude immunodominant epitopes for which no published evidence supports their beneficial effects on viral control, (iii) extensions to cover flanking regions known to affect epitope processing $[47,48]$ and (iv) introduction of single amino acid changes to cover common drug-resistance mutations for which maintained immunogenicity of the resistance variants had been reported [48-50]. Further refinement also included cases where the reported epitopes were originally not identified in the context of consensus clade B sequence [51] and sequence truncations to avoid the presence of "forbidden" residues that are essentially never found on C-terminal ends of HLA class I restricted T-cell epitopes [44,52]. Finally, two additional regions in Gag were incorporated to complete the coverage of previously described hot-spots of $\mathrm{CD} 4^{+} \mathrm{T}$ helper cell activity [53]. These two segments partially overlapped with two of the most conserved regions of Gag p24 [19] that had been shown to be preferentially targeted by HIV-1 controllers and also include the protective B27 KK10 and B14 DA9 CTL epitopes [27]. The final sequence comprised 16 segments ranging from 11-78 amino acids in length representing Gag (45\%), Pol (44\%), Vif (8\%) and Nef (3\%) sequences (Table 3). Linkers between segments consisted of either single, dual or triple alanine residues, and were included with the aim of inducing preferential

\begin{tabular}{lll}
$\begin{array}{l}\text { Table } 3 \text { Distribution and length of the } \mathbf{1 6} \text { final HIV-1 } \\
\text { segments included in the HTI sequence }\end{array}$ \\
\hline HTI segments & Length (AA) & HIV-1 protein \\
\hline S1 & 78 & Gag-p17 \\
S2 & 14 & Gag-p24 \\
S3 & 11 & Gag-p24 \\
S4 & 60 & Gag-p24 \\
S5 & 14 & Gag-p24 \\
S6 & 15 & Gag-p24 \\
S7 & 27 & Gag-p15 \\
S8 & 55 & Prt \\
S9 & 17 & RT \\
S10 & RT \\
S11 & 55 & RT \\
S12 & 34 & Int \\
S13 & 34 & Int \\
S14 & 17 & Vif \\
S15 & 26 & Vif \\
S16 & 19 & Nef \\
Total (incl. linker) & 13 & \\
\hline & 529 & \\
\hline & &
\end{tabular}

proteolytic cleavage between segments and to avoid premature epitope digestion [47,54].

The final linear HTI sequence had a total length of 529 amino acids and included a high density of both $\mathrm{CD}^{+}$and $\mathrm{CD}^{+}{ }^{+} \mathrm{T}$-cell epitopes across all protein subunits restricted by at least 42 different HLA alleles $(\mathrm{n}=$ 55 well-characterized optimal defined CTL epitopes [55] and 6 most frequently targeted $\mathrm{CD} 4^{+} \mathrm{T}$ helper epitopes in Gag [53], Table 4). Of note, $14 \mathrm{Gag} \mathrm{CD}^{+} \mathrm{T}$ cell 'promiscuous' epitopes (recognized in the context of two or more DRB alleles) [7] were covered by the final HTI sequence as well. Importantly, no overrepresentation of HLA-B27 or HLA-B57 supertype-restricted epitopes was observed, which is in line with the unbiased general population screening that provided the data for the identification of beneficial OLP signal (Figure 1A). The sequence was also analyzed for its coverage of particularly vulnerable immune targets based on recently published viral fitness data for Gag p24 sequence mutations [56]. Of the 135 Gag p24 sites analyzed by Rihn and colleagues [56], 72 were covered by HTI. Of these, 58 (80\%) showed high vulnerability for mutations and caused massive $(>50$ fold) reductions in viral replicative fitness. This was a significantly higher proportion of vulnerable sites than what was observed for the Gag p24 region that was not covered by HTI (a total of 37 deleterious mutants among 63 tested variants, $p=0.005$ ), demonstrating further the preferential coverage of vulnerable sites by HTI.

To confirm that the final HTI sequence design (i.e., including extensions, truncations and substitutions) contained $\mathrm{T}$ cell targets preferentially recognized by individuals with reduced viral loads, an independent cohort of HIV-1 clade B infected individuals was tested for responses to the HTI sequence and compared to responses to the full HIV-1 proteome. Data from 38 elite HIV controllers (EC),

Table 4 CTL optimal epitopes and CD4 ${ }^{+}$T-helper epitope coverage of HTI

\begin{tabular}{llll}
\hline $\begin{array}{l}\text { Protein } \\
\text { location }\end{array}$ & $\begin{array}{l}\text { \# of CTL } \\
\text { epitopes }^{\mathbf{a}}\end{array}$ & $\begin{array}{l}\text { \# of CD4 } \mathbf{T}^{\mathbf{T} \text { Helper }} \\
\text { Gag epitopes } \\
\text { (>25\% targeted) }^{\mathbf{b}}\end{array}$ & $\begin{array}{l}\text { \# of 'promiscuous' } \\
\text { CD4 }^{+} \text {T cell Gag }_{\text {peptides }^{\mathbf{c}}}\end{array}$ \\
\hline Gag-p17 & 17 & 3 & 6 \\
Gag-p24 & 21 & 2 & 6 \\
Gag-p15 & 3 & 1 & 2 \\
Pol-Prt & 5 & & \\
Pol-RT & 6 & & \\
Pol-Int & 1 & & \\
Vif & 2 & & 14 \\
Nef & 0 & & \\
Total & 55 & 6 & \\
\hline
\end{tabular}

abased on the 'A' list of optimal defined HIV-1 CTL epitopes described in the Los Alamos HIV Immunology Database [55].

$b, c$ described CD4 T-helper epitopes $[7,53]$. 


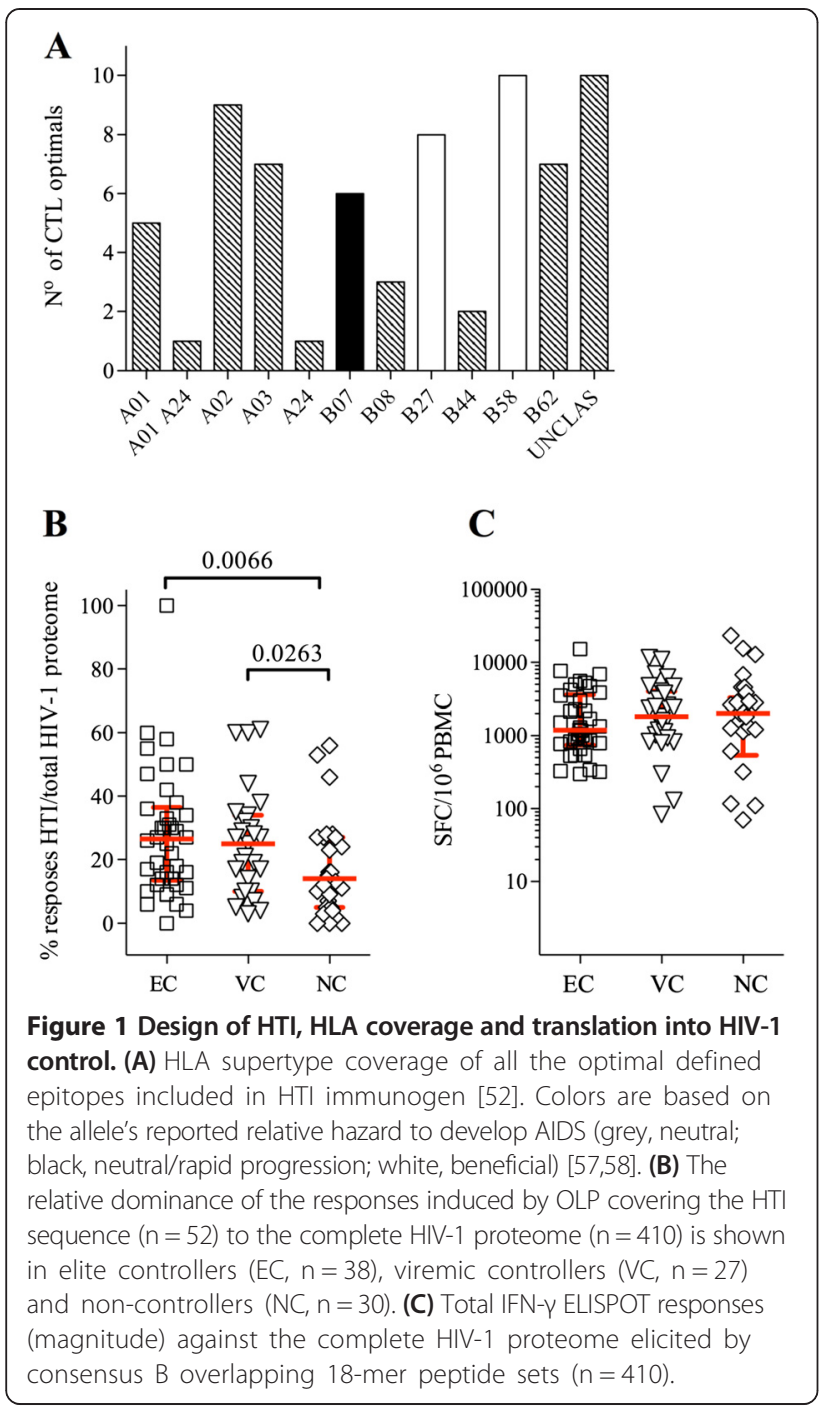

27 viremic controllers (VC) and 30 non-controllers (NC) was collected (Table 1). A significantly stronger focus of the total virus-specific response on targets covered by the HTI was observed in both elite controllers $(26.5 \%$ of total HIV-1 T-cell reactivity targeting HTI) and viremic controllers (25\%) compared to individuals with uncontrolled HIV- 1 infection ( $14 \%, \mathrm{p}=0.0066$ and $\mathrm{p}=0.0263$, respectively) (Figure 1B). These differences were not due to the presence of stronger responses in HIV controllers, as the total magnitude of responses did not differ between groups (Figure 1C). Together, these data indicate that the rational design of HTI resulted in a relatively short, yet highly immunogenic subunit sequence that was especially reactive in HIV controllers and covered a particularly high proportion of vulnerable viral sites.

\section{Expression of HTI plasmid DNA from HEK293 cells}

The HTI sequence was RNA-codon optimized to maximize mRNA processing, transport, stability and translation and was cloned into the pCMVkan expression vector [59] (DNA.HTI). To promote production and secretion of the immunogen, the signal peptide from the human granulocyte macrophage colony-stimulating factor (GM-CSF) was added at the amino-terminus of HTI (Figure 2A) $[17,18,40]$. Upon transient transfection, we analyzed expression of the FLAG-tagged HTI by fluorescent microscopy and found that the protein localized to punctate foci in the cytoplasm of HeLa cells (Figure 2B). The localization of HTI protein was also evaluated from cell extracts and supernatants of transiently transfected HEK293 cells by Western immunoblots (Figure 2C) probed with an anti-FLAG (lanes 1-4) or an anti-p24 ${ }^{\text {gag }}$ antibody (lanes 5-8). The HTI protein migrated at $\sim 50 \mathrm{kDa}$ and was only found in the cell-associated fraction (Figure 2C). We noted lower levels of HTI protein at $48 \mathrm{hrs}$ compared to $24 \mathrm{hrs}$ post transfection (lanes 2 and 4; lanes 6 and 8). To quantitate production from transfected cells, serial dilutions of the p5 $5^{\mathrm{gag}}-$ FLAG and HTI-FLAG proteins were analyzed by Western blots using the common FLAG epitope and a standard FLAG-tagged p55 $5^{\text {gag }}$ protein. A side-by-side comparison in transfected HEK293 cells showed that expression of p55 $5^{\text {gag }}$ increased $\sim 2 \mathrm{x}$ over time ( 280 ng at $24 \mathrm{hrs} ; \sim 600 \mathrm{ng}$ at $48 \mathrm{hrs}$ ), while HTI levels were $\sim 2 \mathrm{x}$ decreased ( 22 $\mathrm{ng}$ at $24 \mathrm{hrs} ; \sim 9.5 \mathrm{ng}$ at $48 \mathrm{hrs}$ ) (Figure 2D). Thus, these data indicate that HTI protein accumulates intracellularly and is significantly less stable than $\mathrm{p} 55^{\mathrm{gag}}$. This was further confirmed by the analysis of HTI-FLAG protein pulled down with anti-FLAG antibody, which allowed the amount of protein loaded per lane to be increased. The Western immunoblot analysis revealed several shorter bands in addition to the full-length HTI protein, possibly reflecting processed products (Figure 2E).

DNA plasmid vaccination in C57BL/6 mice elicits broad and balanced T-cell responses to all protein components of HTI To examine the immunogenicity of HTI, groups of five C57BL/ 6 mice were vaccinated twice ( 0 and 4 weeks) by intramuscular (IM) injection combined with in vivo electroporation (EP) (Figure 3A). DNA.HTI vaccination was compared to a control group that received a mixture of 3 plasmids encoding full-length $\mathrm{p} 55^{\text {gag }}$, Pol and a NefTat-Vif fusion protein (DNA.COMB). The magnitude and breadth of the vaccine-induced T-cell response were assessed in splenocytes collected 2 weeks after the $2^{\text {nd }}$ vaccination (week 6) by an IFN- $\gamma$ ELISPOT assay using two sets of peptide pools: (i) 8 overlapping peptide pools covering the HTI sequence and assembled in separate pools for each protein subunit included in HTI (HTI pool-1 to pool-8) and (ii) 19 additional peptide pools spanning the full-length sequences of Gag ( $n=6$ pools), Pol $(n=8)$, Nef $(n=2)$, Tat $(n=1)$, and Vif $(n=2)$. These pools were used to assess responses to HTI itself and to define the 


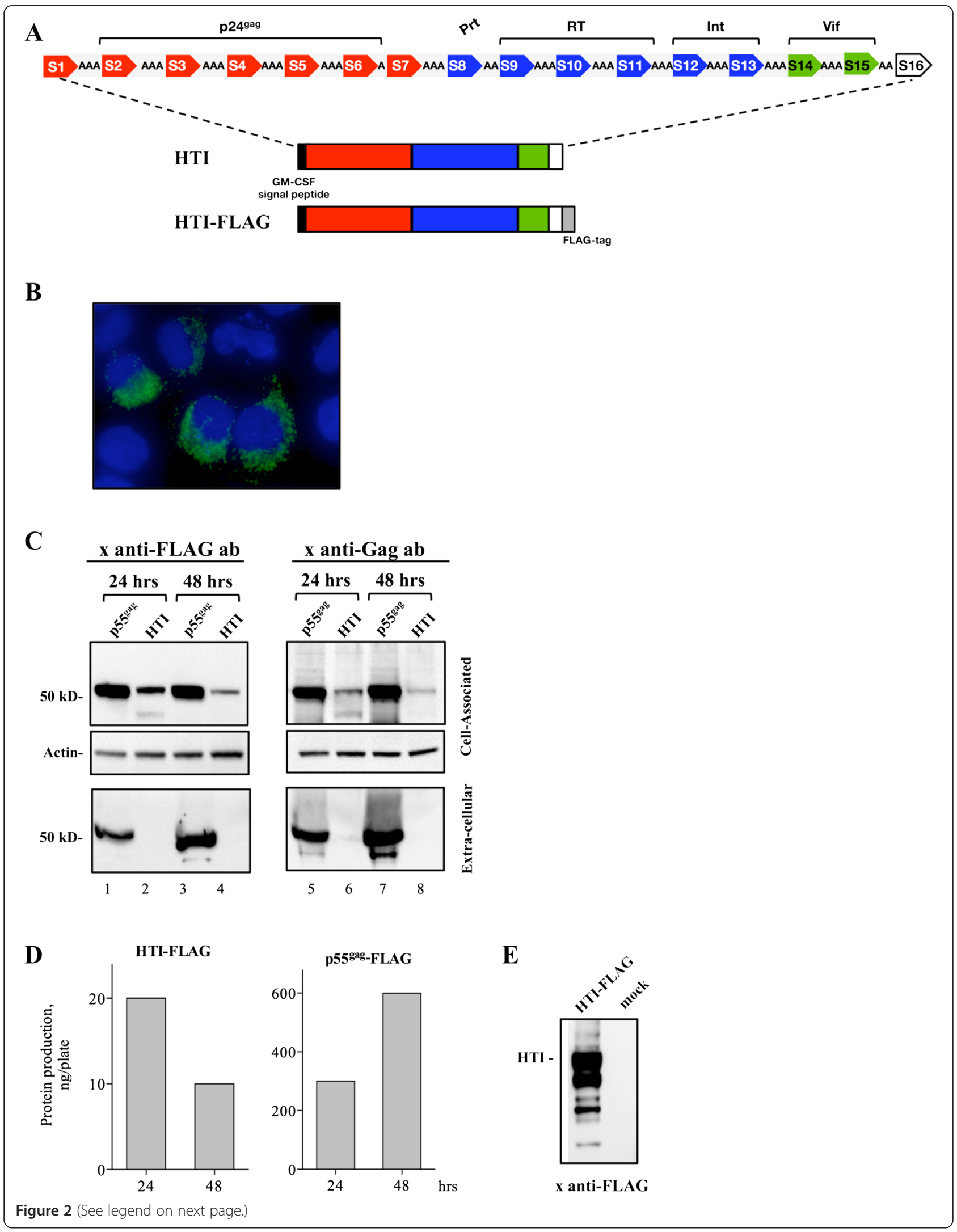


(See figure on previous page.)

Figure 2 Expression of DNA.HTI. (A) The HTI protein is composed of 16 individual segments arranged linearly and linked via 1-3 alanine amino acid linkers and contains the GM-CSF signal peptide for better secretion. Total length of HTI protein is 529 aa, including alanine linkers. (B) Subcellular localization of HTI protein is shown in HeLa-derived HLtat cells transfected with DNA.HTI-FLAG and fixed. The HTI-FLAG protein was visualized with anti-FLAG primary antibody followed by Alexa-Fluor 488 conjugated secondary antibody and the nuclei were visualized with DAPI and a merged image is shown. (C) Plasmid DNA (250 ng) expressing HTI or p55 ${ }^{\text {gag }}$ with or without FLAG were transfected in HEK293 cells. The cultures were harvested after 24 hrs and 48 hrs and proteins in cell-associated (top panel: 1/100) and extra-cellular (bottom panel: 1/150) fractions were resolved on a 12\% NuPAGE Bis-Tris gel. Western immunoblots were analyzed using an anti-FLAG-HRP antibody (lanes 1-4) or a goat anti-p24 ${ }^{\text {gag }}$ antiserum followed by anti-goat lgG-HRP labeled antibody (lanes 5-8) and were visualized using enhanced ECL. The membranes were probed with an anti-beta actin antibody to control for equal loading of the cell-associated fractions. (D) The serially diluted extracts with cell-associated and extra-cellular fractions for p55 $5^{\text {gag }}$-FLAG and cell-associated fraction of HTI-FLAG proteins were analyzed together

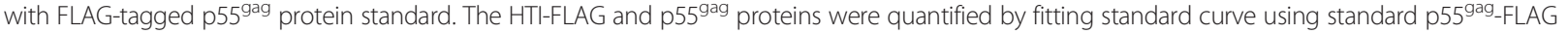
protein. (E) Analysis of a 20-fold concentrated sample (compared to panel C) containing HTI-FLAG by Western immunoblot using anti-FLAG antibody.

responses directed to the HTI portion in animals vaccinated with the full-length protein sequences.

Although the HTI sequence was only a fraction of the combined length of the full-protein sequence in the DNA.COMB (529 amino acids vs 2,000 residues), equally broad responses to the 8 peptide pools covering the HTI sequence were detected after vaccination with the DNA.HTI vaccine [median of 4 reactive pools (range $2-5)$ ] or DNA.COMB [median 2 reactive pools (range 1-3), $\mathrm{p}>0.05$ ] (Figure 3B). Similarly, the magnitudes of the HTIspecific responses were comparable in the two groups (Figure 3C). Importantly, six of the eight protein subunits in the HTI immunogen sequence were targeted at least once in the mice immunized with DNA.HTI, while only 4 peptide pools were reactive in animals vaccinated with DNA.COMB ( $>0.05$, Table 5). In line with this data and as hypothesized, mice immunized with plasmids encoding the full-length protein sequences mounted responses largely (74\%) towards regions not covered by the HTI and showed a strong dominance of Gag-specific T-cell activity (Figure 3D). Polychromatic flow cytometry analysis further revealed that the HTI-specific responses in the DNA.HTI were mediated primarily by $\mathrm{CD}^{+} \mathrm{T}$ cell (not shown). Although Gag was the most potent target in the DNA.HTI vaccinated animals as well (median of $55 \%$ of the total magnitude), the pattern of responses was shifted to a more balanced hierarchy (Gag $>$ Pol $>$ Vif $>$ Nef) (Figure 3E), which was representative of the relative length of the different protein subunits in the HTI immunogen.

To determine the immunogenicity of potential junctional neo-epitopes located between the 16 segments of the HTI sequence, all individual overlapping peptides that contained at least one of the three alanine linker residues were tested. Positive responses were only detectable for the linkers joining segments 4-5, 5-6, 8-9 and 12-13 (Additional file 1: Table S1). Importantly, flanking OLP harboring at least 8 residues before or after the AAA sequence also elicited a response in all but one of these cases, indicating that minor $\mathrm{T}$ cell reactivity to epitopes consisting of the full linker sequence was induced.
Finally, mice were assessed for the induction of humoral immune responses upon DNA.HTI vaccination and compared to animals vaccinated with full-length protein sequences. The ability to recognize full-length $\mathrm{p} 55^{\mathrm{gag}}$ and its processing products, the $\mathrm{p} 37^{\mathrm{gag}}$ intermediate (p17 ${ }^{\text {gag }}$ plus $\mathrm{p} 24^{\text {gag }}$ ) and $\mathrm{p} 24^{\text {gag }}$, was assessed by Western blot assay using pooled plasma from immunized mice. Indeed, plasma from DNA.HTI vaccinated mice recognized the full-length and the processed Gag proteins (Figure 3F). Similar data were obtained with DNA.COMB vaccinated mice, although with a stronger signal indicating a higher antibody titer. Plasma samples were also analyzed by HIV-1 p24 ${ }^{\text {gag }}$ ELISA and showed $\sim 2$ log lower antibody titers in HTI-immunized mice compared to mice vaccinated with DNA.COMB (Figure 3G). Thus, these two assays show that humoral responses induced by pDNA.HTI vaccination are able to recognize the mature proteins encoded by $\mathrm{p} 55^{\text {gag }}$.

Together, these data demonstrate that despite lower in vitro accumulation in HEK293 cells, the HTI immunogen was able to induce robust and broadly distributed T-cell responses in DNA.HTI vaccinated mice, comparable in their magnitude to a mixture of plasmids expressing full-length proteins. In addition, the data show that the present HTI subunit design was able to prevent the strong Gag dominance that was induced by the fulllength immunogen approach. The data also show that despite lower relative activity, HTI induces a humoral response that may serve as a tool to monitor vaccination outcome in future vaccine trials.

\section{MVA.HTI boost increases responses after DNA prime}

Poxvirus-vectors have shown great potential as HIV-1 vaccines and are an attractive choice to induce strong $\mathrm{CD}^{+}$T-cell responses [42,60,61]. MVA.HTI (M) was generated and used in $\mathrm{C} 57 \mathrm{BL} / 6$ mice to compare different heterologous prime-boost combinations with DNA.HTI (D). Vaccines were delivered using $100 \mu \mathrm{g}$ of DNA.HTI and $10^{6} \mathrm{pfu}$ of MVA.HTI by IM injection (Figure 4A). Responses were measured 2 weeks after the last vaccination using pools of overlapping peptides (147 peptides, 
A

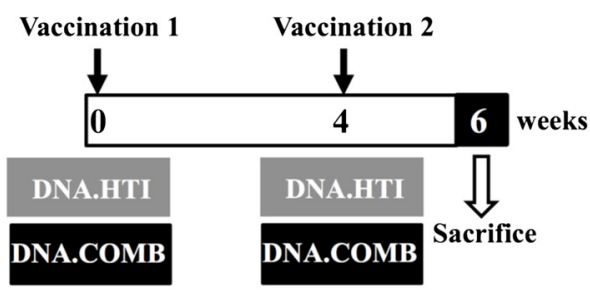

B
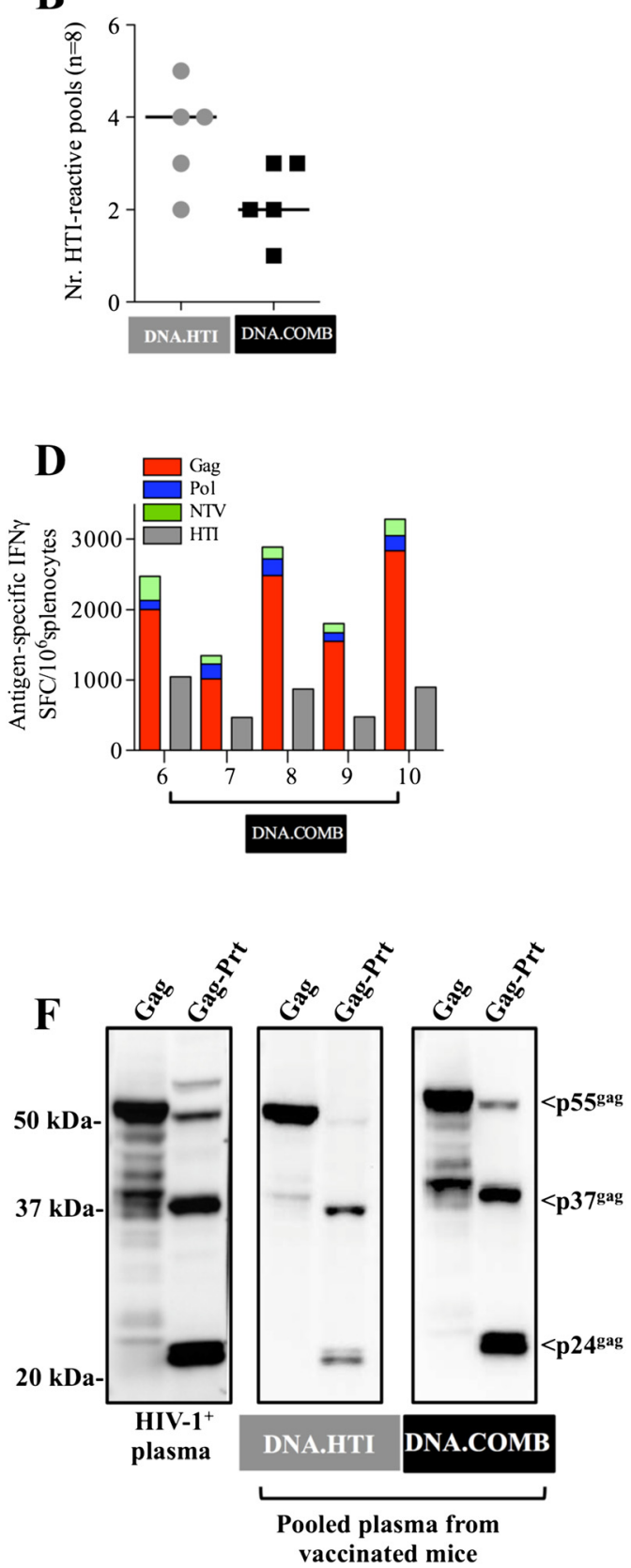

C
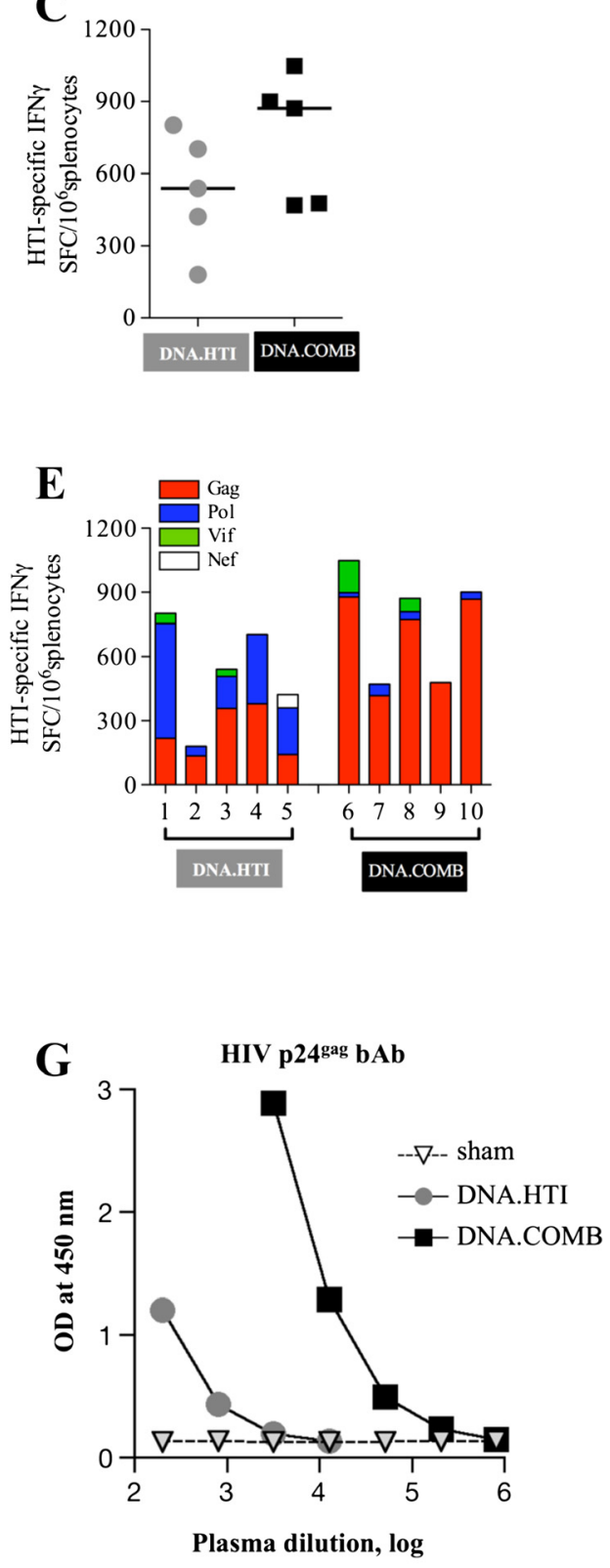

Figure 3 (See legend on next page.) 
(See figure on previous page.)

Figure 3 Balanced immunogenicity upon vaccination with DNA.HTI in mice. (A) Vaccination schedule. Groups of mice ( $\mathrm{n}=5$ ) were vaccinated twice by $\mathrm{IM}$ injection followed by in vivo electroporation (EP) using $20 \mu \mathrm{g}$ DNA.HTI and a mixture of 3 plasmids encoding for full-length $\mathrm{p5}^{\mathrm{gag}}$, Pol and a Nef-Tat-Vif fusion protein (DNA.COMB). Cellular immune responses were measured from thawed splenocytes by IFN- $\gamma$ ELISPOT 2 weeks after the $2^{\text {nd }}$ vaccination using 8 peptide pools covering the HTI sequence. (B) The number of HTI positive responses (reactive pools) in mice immunized with $20 \mu \mathrm{g}$ DNA.HTI or DNA-COMB is shown. (C) Total magnitude of the HTI-specific IFN- $\gamma$ responses is depicted from the mice shown in panel B. (D) Comparison of the IFN- $\gamma$ responses in mice vaccinated with DNA.COMB targeting the regions included in the HTI (grey bars) and the total IFN- $\gamma$ specific response to peptide pools spanning the complete Gag, Pol, NTV. (E) Distribution of HTI-specific induced IFN- $\gamma$ responses against Gag, Pol, Vif and Nef in mice from panel B is shown (DNA.HTI in mice 1-5; DNA.COMB in mice 6-10) using peptide pools spanning the protein sequences included in HTI. (F) Binding antibodies to Gag were detected by Western immunoblot. The membranes contain Gag proteins

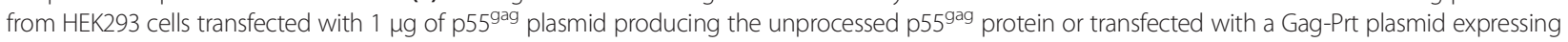
$\mathrm{p} 55^{\mathrm{gag}}$, the processing intermediate $\mathrm{p} 37^{\mathrm{gag}}$ (p2 $4^{\mathrm{gag}}$ and $\mathrm{p} 17^{\mathrm{gag}}$ ) and processed $\mathrm{p} 24^{\mathrm{gag}}$ proteins. Membranes were probed with human sera from an HIV-infected individual or pooled plasma from mice immunized with 20 Mg of DNA.HTI and DNA.COMB (at a 1:100 dilution). (G) Anti-HIV-1 p249ag antibodies were measured in pooled plasma from DNA.HTI and DNA.COMB vaccinated C57BL/6 mice by a standard clade B p24 ${ }^{\text {gag }}$ ELISA.

The graph shows absorbance (optical density, OD).

distributed in 16 linear pools spanning the HTI sequence, including the junctional regions).

DD immunization elicited responses in 3 out of 5 mice, whereas $100 \%$ of the animals showed responses after DDD vaccinations with a trend to increased levels compared to a DD regimen only (Figure 4B-C). A subsequent MVA.HTI boost after two or three DNA prime vaccinations led to higher responses with significantly higher magnitudes (median total magnitude of 777 vs 2,865 IFN- $\gamma$ SFC/million splenocytes after DDD and DDDM, respectively, $\mathrm{p}=0.0087$; Figure $4 \mathrm{C}$ ). To rule out that the boosted response observed was driven by the absolute number of immunizations rather than an heterologous prime-boost strategy, the immunogenicity of
DDD, DDDD vs. DDDM vaccine regimens was assayed in an independent experiment. While a fourth DNA vaccination did not augment responses any further, a significant increase in the total magnitude of responses was found after a single MVA.HTI boost (Figure 4D), reaching in some animals more than $4,000 \mathrm{SFC} / 10^{6}$ spleen cells. As observed for the DDD only vaccinations, a similar balanced and broad response to most of the protein-subunits included in the immunogen was observed in all animals boosted with MVA.HTI (Figure 4E). Nef and Gag-p15 specific responses were only detected in 1 of 6 animals, possibly due to the short length of these two regions (13 and 27 amino acids, respectively; Table 3).

Table 5 Distribution of HTI-specific responses and number of mice with responses to each protein subunit

\begin{tabular}{|c|c|c|c|c|}
\hline \multirow[b]{2}{*}{ HTI segments } & \multirow[b]{2}{*}{ HIV-1 protein } & \multirow[b]{2}{*}{ HTI pool (\#peptides/pool) } & \multicolumn{2}{|c|}{ Number of animals with positive response $(n=5)$} \\
\hline & & & DNA.COMB & DNA.HTI \\
\hline$\overline{S 1^{a}}$ & Gag-p17 & Pool1 (10) & 0 & 2 \\
\hline S2 & Gag-p24 & Pool2 (12) & 5 & 5 \\
\hline S3 & Gag-p24 & & & \\
\hline S4 & Gag-p24 & & & \\
\hline S5 & Gag-p24 & & & \\
\hline S6 & Gag-p24 & & & \\
\hline S7 & Gag-p15 & Pool3 (3) & 0 & 0 \\
\hline $58^{\mathrm{a}}$ & Prt & Pool4 (6) & 2 & 5 \\
\hline $59^{\mathrm{a}}$ & RT & Pool5 (11) & 2 & 4 \\
\hline $\mathrm{S} 10^{\mathrm{a}}$ & RT & & & \\
\hline S11 & RT & & & \\
\hline $\mathrm{S} 12$ & Int & Pool6 (4) & 0 & 0 \\
\hline $\mathrm{S} 13$ & Int & & & \\
\hline S14 & Vif & Pool7 (4) & 2 & 2 \\
\hline S15 & Vif & & & \\
\hline $\mathrm{S} 16^{\mathrm{a}}$ & Nef & Pool8 (2) & 0 & 1 \\
\hline
\end{tabular}

asegments with increase in HTI-specific responses in DNA.HTI and DNA.COMB. 


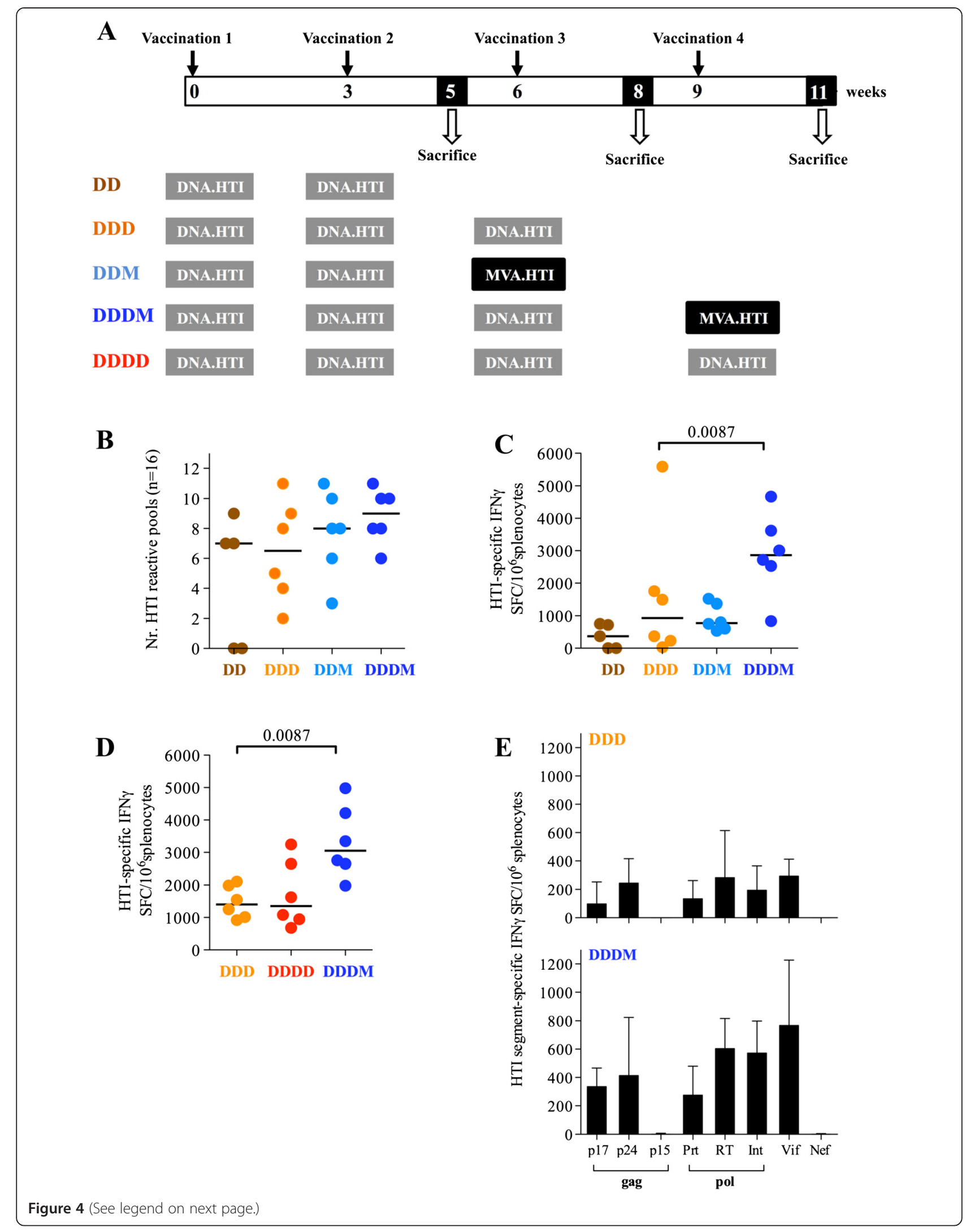


(See figure on previous page.)

Figure $4 \mathrm{HTI}$ responses are boosted by MVA.HTI vaccination. (A) Vaccination schedule of mice ( $n=6 / \mathrm{group}$ ) vaccinated with different prime/boost regimens including: 2xDNA (DD), 3xDNA (DDD), 4xDNA (DDDD); DNA prime followed by MVA boost (DDM and DDDM). 147 peptides (15-mers, overlapping by 11 residues) spanning the entire HTI sequence (including the leader sequence and linkers regions) were used in an IFN- $\gamma$ ELISPOT assay to assess immunogenicity of the different regimens. Data from 1 animal in the DD group was not evaluated due to high background result in the ELISPOT assay. Breadth (B) and magnitude (C-E) of induced HTI-specific IFN- $\gamma$ responses in different groups of mice to a set of 16 peptide pools spanning the different protein segments is shown either as total HTI-specific responses (C, $\mathbf{D})$ or as response to individual proteins (E). Bars represent median values. Median with interquartile range is shown in panel $\mathbf{E}$. Panel $\mathrm{D}$ is an independent mouse experiment conducted to compare responses after DDD, DDDD and DDDM vaccination.

\section{HTI vaccination induces robust antigen-specific memory} $T$ cells in rhesus macaques

Next, four outbred Indian rhesus macaques with different MHC class I haplotypes (Table 6), none expressing Mamu-B*08 [62], were vaccinated via the IM route combined with in vivo electroporation at 0, 1 and 3 months with DNA.HTI (Figure 5A). A macaque IL-12 encoding DNA plasmid was co-administered as molecular adjuvant. The HTI-specific cellular immune responses were measured in PBMC upon stimulation with the immunogenmatched peptide pools and analyzed by intracellular cytokine staining. Analysis of the immune responses at 2 weeks after the $2^{\text {nd }}$ DNA vaccination showed robust induction of HTI-specific IFN- $\gamma^{+} \mathrm{T}$ cells in all macaques (Figure 5B). The responses increased with the $3^{\text {rd }}$ DNA vaccination yielding a range of $0.4-1.5 \%$ of total $\mathrm{T}$ cells reactive to HTI peptides.

In three (R678, R679, R680) out of the four animals, the responses induced by HTI vaccination were mediated primarily by $\mathrm{CD}^{+}$effector memory $\mathrm{T}$ cells (EM, CD28 ${ }^{-}$ $\mathrm{CD} 5^{+}$) with significant contributions by the $\mathrm{CD} 4^{+}$and $\mathrm{CD}^{+}$central memory $\mathrm{T}$ cell subsets $\left(\mathrm{CM}, \mathrm{CD} 28^{+} \mathrm{CD}^{+} 5^{+}\right.$) (Figure $5 \mathrm{C}$ ). In contrast, macaque R681 developed responses dominated by $\mathrm{CD}^{+}{ }^{+} \mathrm{T}$ cells and, overall, had the lowest level of recognition of the HTI epitopes. Although we noted a contraction of the responses over the following 4.5 months, these responses persisted and were still in the range as measured after the DD vaccination (range 0.1$0.6 \%$ IFN- $\gamma$ T cells), supporting the longevity of the DNAvaccine induced immunity using an IM/EP approach $[45,63]$. At this time point, the animals were boosted with recombinant MVA.HTI (Figure 5A), which led to a 3- to 20 -fold increase in the response, reaching $0.4-3.2 \%$ IFN- $\gamma$ $\mathrm{T}$ cells (Figure $5 \mathrm{C}$ ). In two of animals (R678, R680) the levels were higher than the peak response after three DNA immunizations. The responses persisted over the 3 months of follow-up and were successfully expanded in all 4 animals by a $2^{\text {nd }}$ MVA.HTI vaccination. Macaque R680 showed an exceptionally high persistence of responses ( $\sim 2 \%$ of IFN- $\gamma^{+}$T cells), which were only weakly boosted by the $2^{\text {nd }}$ MVA boost. Overall, MVA.HTI was powerful in expanding DDD induced responses with limited benefit noted upon the $2^{\text {nd }}$ MVA.HTI boost.

\section{HTI vaccine induces antigen-specific memory T cells with cytotoxic potential}

We also analyzed the cytotoxic potential of the vaccineinduced $\mathrm{T}$ cell responses using Boolean gating strategies. Subsets of the antigen-specific $\mathrm{CD}^{+}$(Figure 6A) and $\mathrm{CD} 4^{+}$ (Figure 6B) $\mathrm{T}$ cells were characterized by their granzyme $\mathrm{B}$ $(\mathrm{GzmB})$ content and ability to degranulate, as determined by surface expression of CD107a after antigen stimulation [64]. This analysis revealed the majority of IFN $-\gamma^{+} \mathrm{CD} 8^{+} \mathrm{T}$ cells being double positive for $\mathrm{CD}_{107 \mathrm{a}^{+}}$and $\mathrm{GzmB}^{+}$ (Figure 6A), both after DNA prime and MVA boost vaccinations. Similar to the memory subsets, these cytotoxic phenotypes did not significantly change over time. The analysis of antigen-specific $\mathrm{CD} 4^{+} \mathrm{T}$ cells (Figure 6B) showed that although the majority of these cells were $\mathrm{GzmB}^{-}$and $\mathrm{CD} 107 \mathrm{a}^{-}$, this subset also contained a small fraction of single $\mathrm{CD} 107 \mathrm{a}^{+}$or double positive $\left(\mathrm{GzmB}^{+}\right.$ $\mathrm{CD}_{107^{+}}$) cells. In this aspect the four animals showed a consistent pattern of effector functions, even though $\mathrm{CD}^{+} \mathrm{T}$ cells dominated the vaccine-induced response in animal R681.

\section{$\mathrm{HTI}$ vaccine induces broadly distributed responses in rhesus macaques}

Finally, the distribution of responses across the different protein-subunits contained in the HTI immunogen was assessed at the peak after the DNA vaccinations (DDD) and after the MVA.HTI boosts (Figure 7). A set of 16

Table 6 Age, gender and haplotypes of macaques

\begin{tabular}{|c|c|c|c|c|c|c|c|c|c|c|c|}
\hline Animal & Age (yrs) & Sex & $A * 01$ & $A * 02$ & $A * 08$ & $A * 11$ & $B * 01$ & $B * 03$ & $B * 04$ & $B * 08$ & $B * 17$ \\
\hline R678 & 3 & Male & Neg & Neg & Pos & Neg & Neg & Neg & Pos & Neg & Pos \\
\hline R679 & 3 & Male & Neg & Neg & Neg & Neg & Neg & Neg & Neg & Neg & Neg \\
\hline R680 & 3 & Male & Neg & Neg & Neg & Neg & Neg & Neg & Neg & Neg & Neg \\
\hline R681 & 3 & Male & Neg & Neg & Pos & $\mathrm{Neg}$ & $\mathrm{Neg}$ & $\mathrm{Neg}$ & Neg & Neg & Neg \\
\hline
\end{tabular}


A

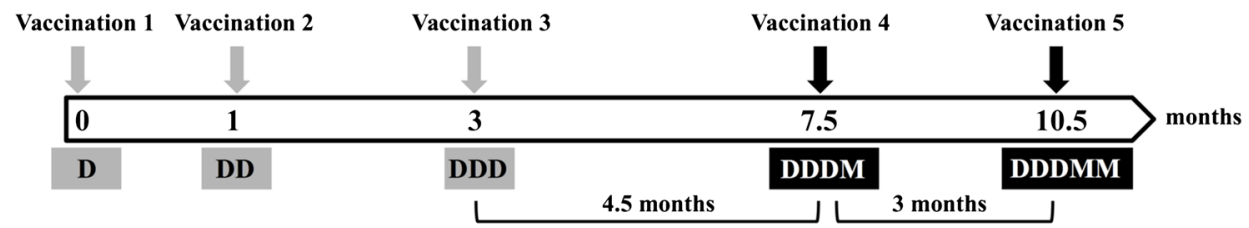

B
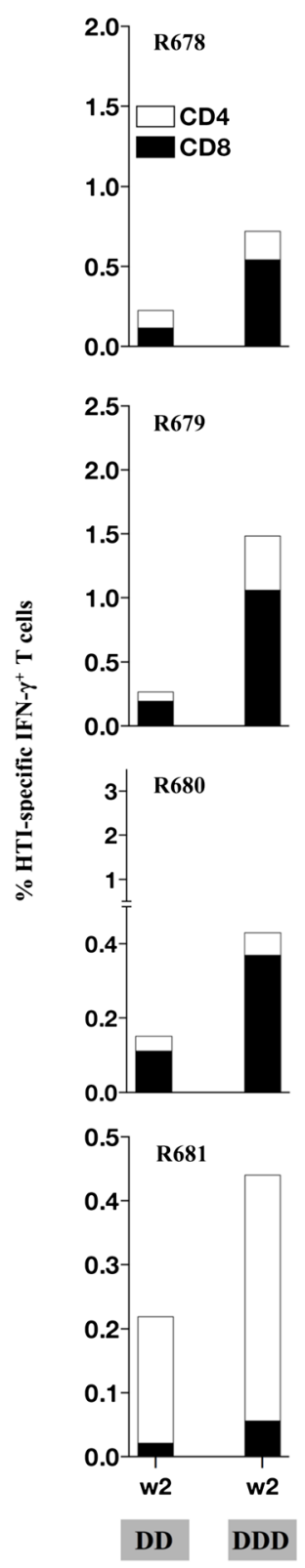

C
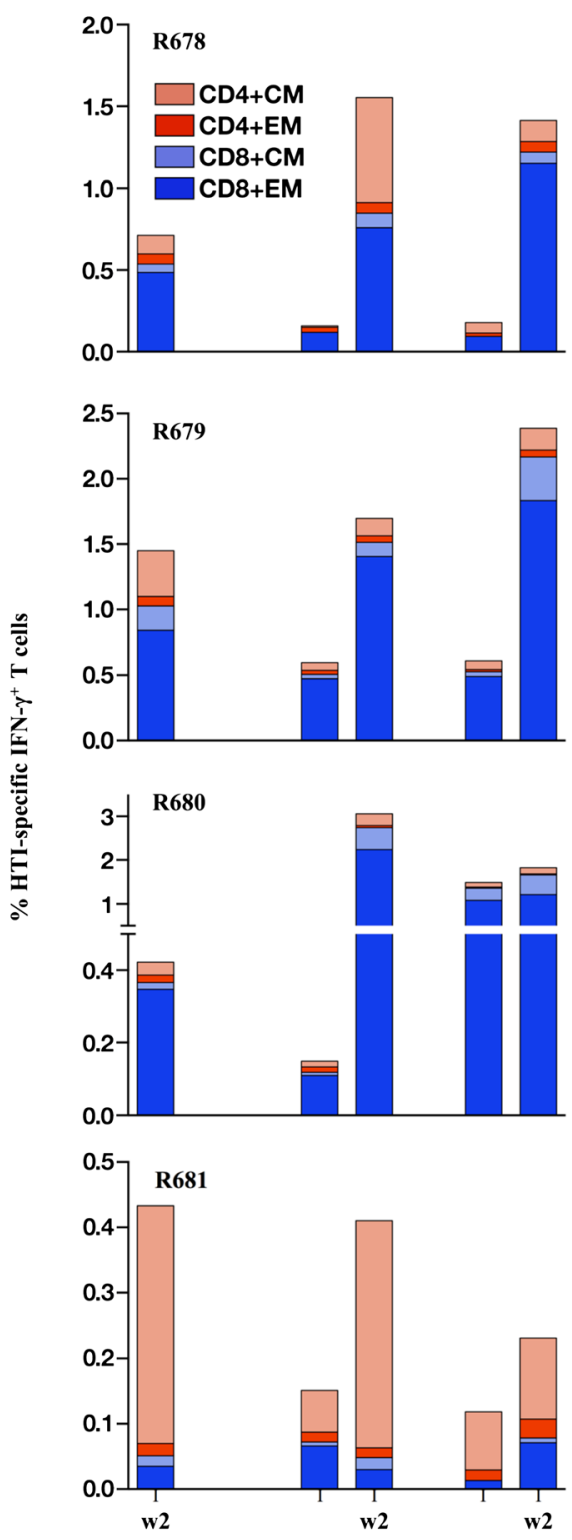

DDD DDDM DDDMM

Figure $\mathbf{5}$ (See legend on next page.) 
(See figure on previous page.)

Figure 5 HTI vaccine induces robust memory T cell responses in rhesus macaques. (A) Vaccination schedule. Four macaques (R678, R679, R680, R681) were vaccinated 3x (0, 1, 3 months) with DNA.HTI and IL-12 DNA and subsequently with two MVA.HTI boosts. Cellular immune responses were measured by intracellular cytokine staining after the different vaccinations as indicated. (B) The frequency of HTI-specific IFN- ${ }^{+} \mathrm{T}$ cells was measured after the DNA vaccinations using peptide pools covering the complete HTI sequence. The HTI-specific CD4 ${ }^{+}$(open bars) and $\mathrm{CD}^{+}$(filled bars) T cells are shown for each animal as number of reactive peptide pools. (C) The frequencies of HTI-specific IFN- $\gamma^{+} \mathrm{T}$ cells with central memory $\left(\mathrm{CM} ; \mathrm{CD}_{28}{ }^{+} \mathrm{CD} 95^{+}\right)$and effector memory $\left(\mathrm{EM} ; \mathrm{CD}_{28}{ }^{-} \mathrm{CD} 95^{+}\right)$phenotype are shown over the course of the study.

specific peptide pools (S1-S16), each covering a single segment of the HTI sequence (Table 3), was used to measure responses by flow cytometric intracellular cytokine staining assays. The results show that three DNA vaccinations induced $\mathrm{T}$ cell responses targeting all the proteins represented within HTI, except Nef and recognized a range of 4-7 of the 16 segments (Figure 7, Table 7). Of note, Nef is represented by a single segment of only 13 aa (and includes only three known CTL epitopes [55] restricted by the same $B^{*} 07$ supertype in humans), whereas other proteins were covered by several segments of various lengths (Table 7). Upon the $1^{\text {st }}$ MVA. HTI boost, the magnitude of the pre-existing responses was increased in all the animals (range 6-8 segments) and additional responses were found in two animals (R678, R680), albeit at low levels. After the $2^{\text {nd }}$ MVA.HTI boost, macaques R681 showed 3 additional responses, while some of the new responses found after the $1^{\text {st }}$ MVA.HTI boost in R678 and R680 were not detectable. Overall, DNA prime-MVA boost showed that 13 of the 16 segments of HTI were immunogenic in macaques (Table 7). As expected the majority of the HTI-specific responses was mediated by $\mathrm{CD}^{+}{ }^{+}$IFN- $\gamma^{+} \mathrm{T}$ cells in R678, R679 and R680 and by CD $4^{+}$IFN $-\gamma^{+}$T cells in R681.

Because the HTI design is based on human, HLArestricted $\mathrm{T}$ cell reactivity data, we did not further finemap the HTI-segments to identify all CTL responses at the single epitope level in the context of each macaque MHC class I allele. Thus, the full breadth of the broad responses induced by HTI in macaques $(81 \%$ of HTI segments) may be underestimated.

\section{HTI vaccine induces humoral responses in rhesus macaques}

We also tested the plasma from the vaccinated macaques upon DNA prime and upon MVA boost for the development of humoral responses to HTI protein (Figure 8A). We found that upon 3 DNA vaccinations, 3 of the 4 animals (R678, R679, R801) developed low levels of antibodies specific for HTI protein. Upon MVA boost all 4 animals showed greatly increased responses. The plasma was further tested by ELISA for its ability to recognize p24 ${ }^{\text {gag }}$. One of the macaques R678 also showed positive ELISA responses after the MVA boosts, indicating that the HTI vaccine sequence also induced humoral immune responses at least against some of its components.
Together, we present here the development and preclinical testing of a novel HIV-1 T-cell immunogen that has been rationally designed to maximize the induction of effective anti-viral $\mathrm{T}$ cell immunity. Its design is based on some of the largest available datasets of human cellular immunity to HIV-1, which allowed for the identification and inclusion of the most vulnerable $\mathrm{T}$ cell targets within the viral proteome that are associated with control of viremia. Thus, the HIVACAT T-cell Immunogen (HTI) differs conceptually from previous immunogen design approaches that have used full proteins sequences [23-25] or very short protein segments only $[29,65,66]$. This extends to the most promising approaches, including the one developed by Hanke et al. that focuses on conserved regions of the viral proteome [42]. In that design, some regions are included that do not seem to induce broad and strong immune reactivity in natural HIV-1 infection [36] and do not emerge as particularly beneficial targets [28]. Although the reasons for this reduced immunogenicity are unknown and could include subdominant beneficial targets [3], the relevance of such portions of vaccine inserts needs to be revisited. Similarly, immunogens that focus on highly conserved elements (CE) within Gag-p24 were chosen in part because of their preferential reactivity by controllers and since immune response to conserved regions have been associated with virologic control [17-20,28]. However, screening data showed that only select $\mathrm{CE}$ to be more frequently targeted by HIV controllers [27], in line with recent data suggesting that sequence conservation alone is not a reliable measure of vulnerability $[67,68]$. Finally, the favorable design of HTI is further supported by emerging data from studies in post-vaccination samples in the STEP and Phambili trials [69]. In those analyses, the subjects' in vitro antiviral activity (measured by viral replication inhibition assay and associated with in vivo viral control [70] was directly correlated with the extent to which the CD8 $\mathrm{T}$ cell response was focused onto the HTI sequence, but not with the magnitude of responses to the rest of the viral proteome.

The incorporation of $\mathrm{T}$ cell reactivity data from natural HIV-1 infection may make the HTI sequence especially interesting for therapeutic and eradication approaches [71]. In this context, the inclusion of relatively conserved regions may help to cope with the consequences of viral evolution of both circulating and reactivated viruses [72] in chronically infected individuals. At the same time, the 


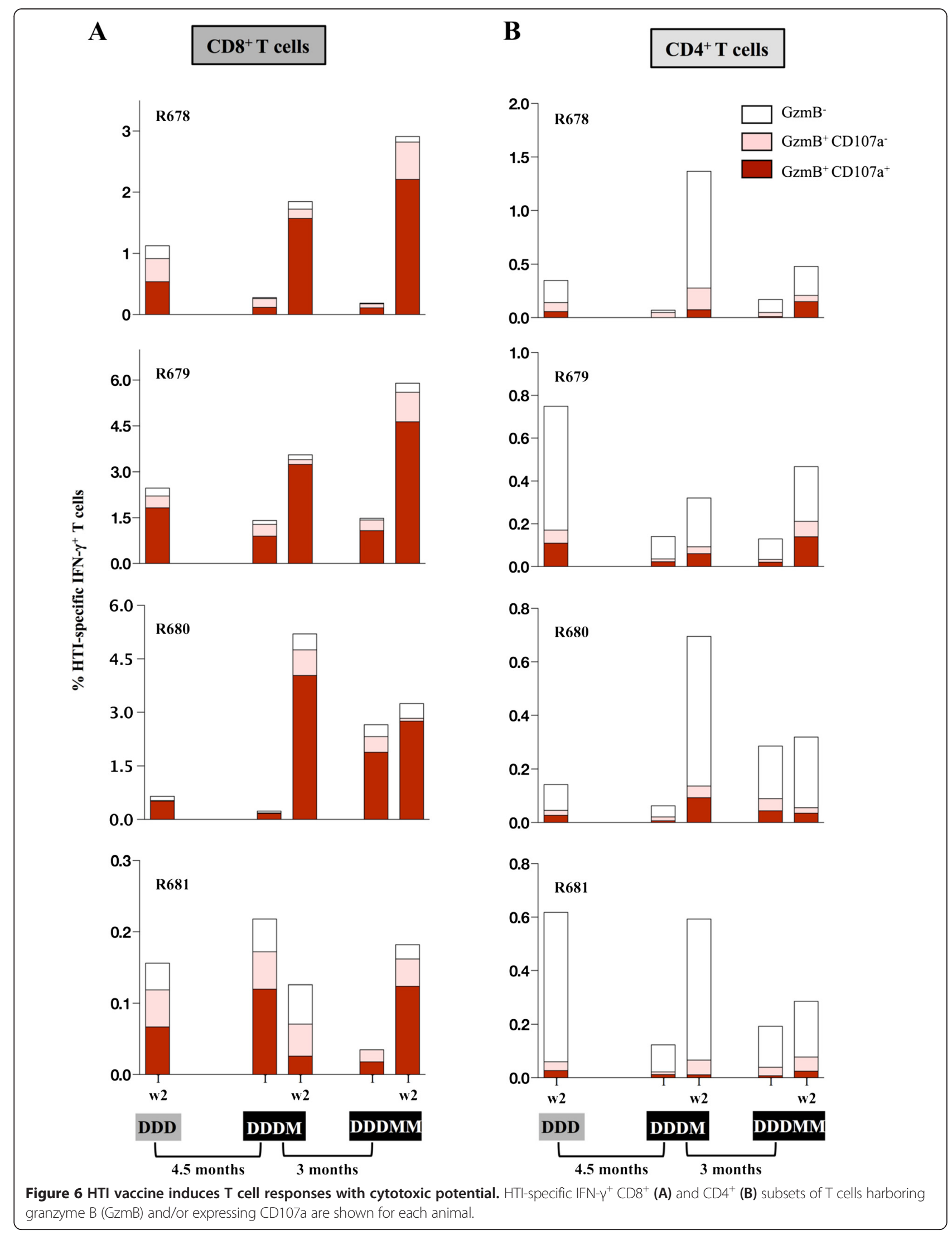




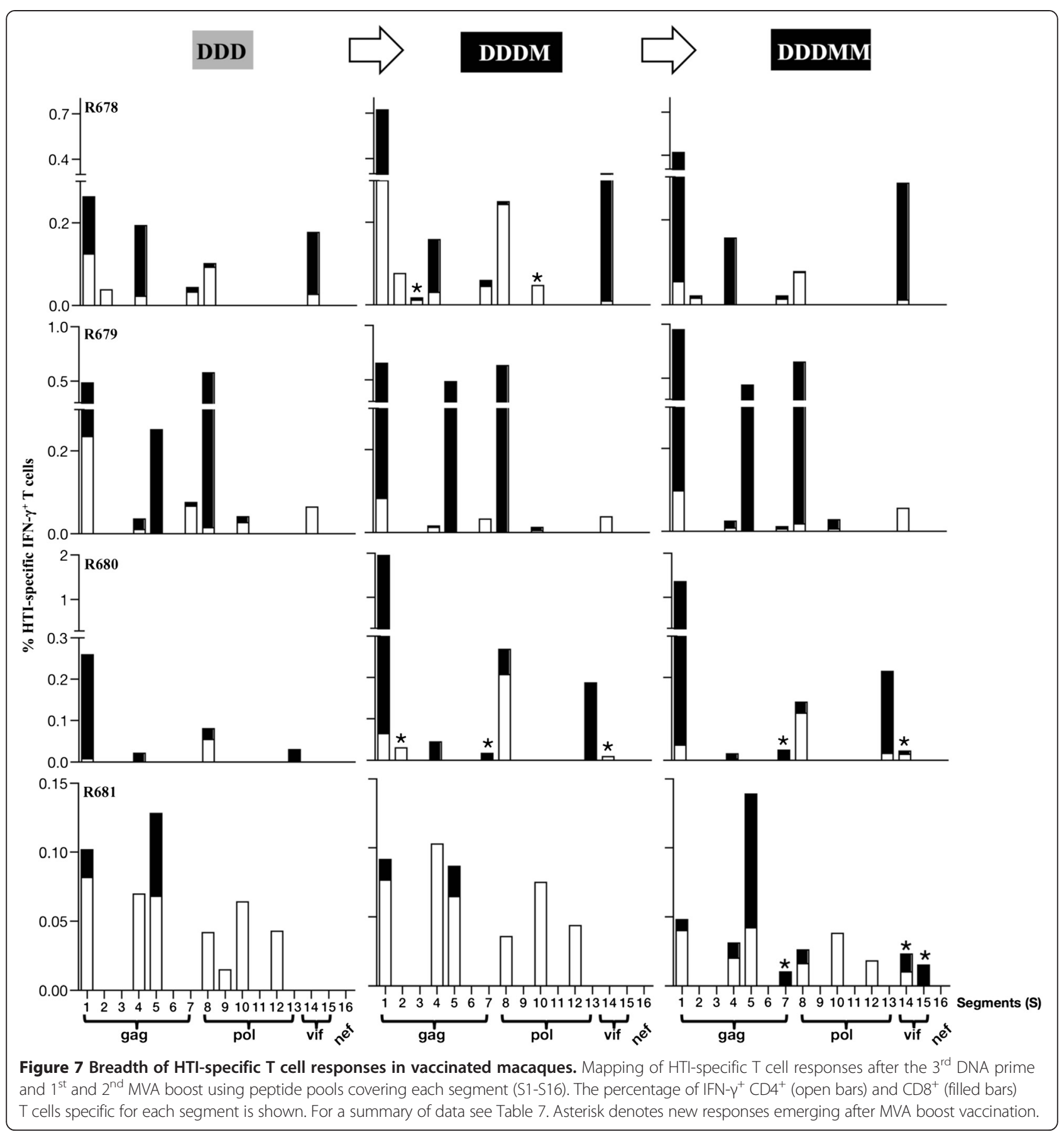

high density of potentially beneficial $\mathrm{CD} 4^{+} \mathrm{T}$-cell epitopes may also help the induction of neutralizing humoral immunity in preventive settings $[6,53]$. In that setting, the focus on most vulnerable regions of the viral proteome could prove crucial if sterilizing immunity cannot be obtained as the induced T-cell responses may help to reduce viral fitness and lower viral set point in breakthrough infections. The induction of such effective antiviral immunity, even though not sterilizing, would still have a far-reaching impact on the epidemic, both by reducing rate of disease progression as well as by lowering the likelihood of further virus transmission. Of note, and although the development of HTI was largely based on immune data from a HIV-1 clade B-infected cohort in Peru, our results are supported by additional analyses in an European clade B-infected cohort (shown here) and a USbased cohort previously described [36]. In addition, viral fitness data, which have been published since the initial 
Table 7 Breadth of cellular immune responses after DNA.HTI prime and MVA.HTI boost using HTI segment-specific peptide pools

\begin{tabular}{|c|c|c|c|c|c|c|c|c|c|c|c|c|c|c|c|c|c|c|}
\hline \multirow[t]{4}{*}{ Animal } & \multirow[t]{4}{*}{ Vaccine } & \multicolumn{7}{|l|}{ Gag } & \multicolumn{6}{|l|}{ Pol } & \multirow{2}{*}{\multicolumn{2}{|c|}{ Vif }} & \multirow{3}{*}{$\begin{array}{l}\text { Nef } \\
16\end{array}$} & \multirow{4}{*}{$\begin{array}{l}\text { \# of positive } \\
\text { segments }\end{array}$} \\
\hline & & \multirow{2}{*}{$\begin{array}{l}\mathrm{p} 17 \\
1^{\mathrm{a}}\end{array}$} & \multicolumn{5}{|c|}{ p24 } & \multirow{2}{*}{$\begin{array}{l}\mathrm{p} 15 \\
7\end{array}$} & \multirow{2}{*}{$\begin{array}{l}\text { Prt } \\
8\end{array}$} & \multicolumn{3}{|l|}{ RT } & \multicolumn{2}{|c|}{ Int } & & & & \\
\hline & & & 2 & 3 & 4 & 5 & 6 & & & 9 & 10 & $\overline{11}$ & $\overline{12}$ & $\overline{13}$ & 14 & $\overline{15}$ & & \\
\hline & & & 14 & 11 & 60 & 14 & 15 & 27 & 55 & 17 & 55 & 34 & 34 & 17 & 23 & 19 & 13 & \\
\hline \multirow[t]{2}{*}{ R678 } & DNA & + & + & & + & & & + & + & & & & & & + & & & 6 \\
\hline & MVA & + & + & $+^{c}$ & + & & & + & + & & $+^{c}$ & & & & + & & & 8 \\
\hline \multirow[t]{2}{*}{ R679 } & DNA & + & & & + & + & & + & + & & + & & & & + & & & 7 \\
\hline & MVA & + & & & + & + & & + & + & & + & & & & + & & & 7 \\
\hline \multirow[t]{2}{*}{ R680 } & DNA & + & & & + & & & & + & & & & & + & & & & 4 \\
\hline & MVA & + & $+^{c}$ & & + & & & $++^{\mathrm{d}, \mathrm{e}}$ & + & & & & & + & $t^{\mathrm{d}, e}$ & & & 7 \\
\hline \multirow[t]{2}{*}{ R681 } & DNA & + & & & + & + & & & + & + & + & & + & & & & & 7 \\
\hline & MVA & + & & & + & + & & $+^{d}$ & + & & + & & + & & $+^{d}$ & $+^{d}$ & & 9 \\
\hline
\end{tabular}

a segment number, S1-S16.

bumber of amino acids per segment.

cnew response detectable after $1^{\text {st }}$ MVA boost only.

${ }^{d}$ new response detectable after $2^{\text {nd }}$ MVA boost.

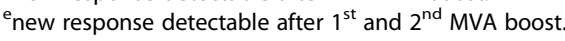

design of this sequence, strongly support the HTI design and its preferential focus on sites that are highly susceptible to debilitating sequence mutations [56,68]. Furthermore, it is also reassuring that HTI in at least some regions overlaps with the HIVCons [42] the Conserved Elements $[17,18]$ and other conserved regions previously proposed to induce protective $\mathrm{T}$ cell responses [31] despite the differences strategies that were the base for these designs.

An important aspect of the present vaccine candidate is its focus on fewer but possibly more effective targets than those that are generally induced by full-protein immunogens. Of particular importance may be the avoidance of responses to highly immunogenic and at the same time variable targets, as these may effectively misdirect the immune response [19]. This is especially the case for HIV-1 Nef, which contains multiple hot spots of high T-cell reactivity. In fact, past reports show that peptide sets spanning Nef contain the single most dominant 18mer peptides that can elicit responses in more than $50 \%$ of the tested individuals [36]. This number is likely even an underestimation as responses to more variable regions are missed by the use of monomorphic peptide test sets $[73,74]$. The same may apply to responses targeting envelope which has shown surprisingly strong immunogenicity in some vaccination trials but which, in our analyses, did not yield any beneficial $\mathrm{T}$ cell targets $[24,28,75]$. The reactivity to potential decoy targets in envelope needs special consideration when using full-length envelope sequences for the induction of humoral responses. In this regard, shorter envelope immunogen designs (i.e. MPER [76]) may provide and advantage as there is less chance of diverting the $\mathrm{T}$ cell immune response to less effective epitopes.
The concern of decoy responses calls into question strategies that intend to overcome diversity by including multiple variants of the same sequence [32-35] as this may further prevent the induction of more beneficial T-cell specificities. As such, it may be beneficial to deal with HIV-1 sequence diversity by ignoring it, rather than trying to incorporating it into vaccine immunogens [77]. The expansion of responses to decoy targets has also important implications when considering HTI as a therapeutic vaccine. As suggested by previous therapeutic trials it may prove difficult to remodel the $\mathrm{T}$ cell response patterns induced during chronic HIV-1 infection by therapeutic vaccination [78-81]. In this case, the use of a vaccine vector with relatively low immunogenicity may help to specifically boost HTI-specific responses while avoiding the expansion of less beneficial $T$ cell specificities that may occur when using viral vectors with more systemic immune activation. For this reason, we elected to express HTI first in a DNA plasmid vector as these allow for repeated administrations without generating vector immunity. In addition, DNA vaccines expressing different forms of simian immunodeficiency virus antigens decrease viremia upon SIVmac251 challenge [45,59].

Overall, murine data accurately predicted the outcome of vaccination in macaques, as in both species broadly directed responses of high magnitude were detected. Especially encouraging was the avoidance of overly immunodominant responses to single epitopes, reflected by the fact that in the macaque model $81 \%$ of the HTI-segments were recognized in the context of heterogeneous MHC haplotypes and after testing only four different animals. Why one animal failed to induce strong CD8 T cell responses and instead mounted broader $\mathrm{CD} 4 \mathrm{~T}$ cell activities 


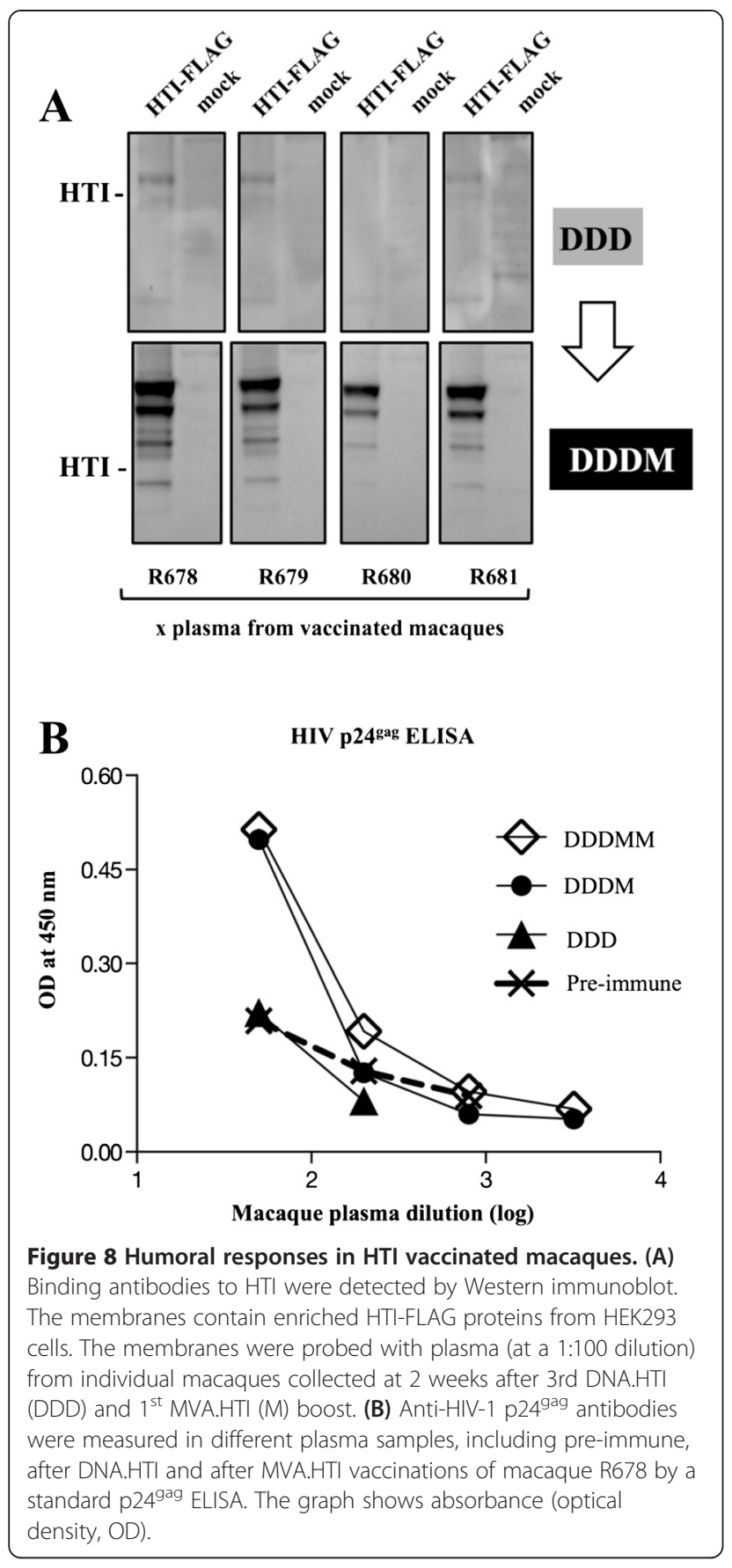

that were not boosted upon repeated MVA vaccination remains unclear. Further analyses in host genetics and/or immune homeostasis (cytokine levles, etc.) could possibly help explain this atypical response pattern and provide some leads to understand the only partial response rates even in the most potent vaccination strategies in SIV infected animals $[82,83]$ Regardless of this, the avoidance of strong immunodominance effects will be a prerequisite for broad $\mathrm{T}$ cell responses in vivo a requirement that HTI, at least in mice and macaques, seems to fulfill as all components of the vaccine were evenly targeted. These observations need to be verified in human clinical trials as the antigen processing preferences and $\mathrm{T}$ cell receptor (TCR) repertoires in humans may be different. The same is true for the HTI-elicited high magnitude of antigenspecific effector memory CD8+ T cells with cytotoxic potential as well as $\mathrm{CD} 4^{+} \mathrm{CM} \mathrm{T}$ cells. Hansen et al,, using RhCMV vectored vaccines, reported that such effectormemory $\mathrm{T}$ cell responses located at the portal-of-entry are able to mediate viral control after SIV amplification in intra-rectally challenged rhesus macaques $[83,84]$. Of note, RhCMV vectored vaccines induced extremely broad responses with a significant altered immunodominance hierarchy compared to response to natural HIV infection, further suggesting that the fine specificity of the vaccineinduced HTI/HIV specific T cell response may prove crucial. Yet, since the HTI design is human data-driven, challenge studies in the macaque model are not really feasible as a) there are no comparable immune reactivity data from sufficiently large and out-bred monkey cohorts available and b) the evolution of SIV variants used in monkey models does not reflect the adaptation processes of HIV to the human population [85]. Thus, human clinical trials are being initiated in the therapeutic vaccination setting as a proof-of-concept to test whether this novel concept of HIV T cell immunogen design will indeed lead to the induction and refocus of broadly co-dominant $\mathrm{T}$ cell responses that can effectively suppress viral replication.

\section{Conclusions}

We present here the design and preclinical-testing of a novel approach to HIV vaccine design, which is based on the identification of beneficial $\mathrm{T}$ cell responses and vulnerable viral targets and their subsequent inclusion in a refined subunit immunogen sequence. Our data show that the immunogen is capable to induce broadly and evenly distributed responses without being affected from strong immunodominance effects. Prime-boost strategies using DNA and MVA vectors elicit responses that exceed magnitudes by most other vaccine concepts and which are of a differentiation phenotype associated with vaccine-induced control of SIV infection in the macaque model. These data support the further development of this and other related functional-data based $\mathrm{T}$ cell vaccine approaches.

\section{Additional file}

Additional file 1: Table S1. Fine-mapping of responses to linker-containing peptides in pDNA-HTI immunized mice.

\section{Competing interests}

$C B, B M$ and $A L L$ are inventors of the $\mathrm{HTI}$ immunogen and a patent application based on this work has been filed (EP12382031.8, 2012). GNP and BKF are inventors on US Government-owned patents and patent applications related to 
DNA vaccines and gene expression optimization. NYS is a full time employee of Inovio Pharmaceuticals and as such receives compensation in the form of salary and stock options. The funders had no role in study design, data collection and analysis, decision to publish, or preparation of the manuscript.

\section{Authors' contributions}

$B M, A L L, C B$ conceived and designed the HTI immunogen. BM, ALL, MR, MC, AM contributed to the recruitment and follow-up in of controller patients and performed the human immunogenicity studies. BM, MR, VK performed the cloning and in-vitro expression studies. BM, MR, AO, JC, VJ, XH performed immunogenicity studies in mice. NS contributed in the studies requiring electroporation. $\mathrm{XH}, \mathrm{MR}, \mathrm{AV}, \mathrm{CA}, \mathrm{BF}, \mathrm{GP}$ performed the studies in macaques. $B M, A V, B F, G P$ and $C B$ undertook the statistical analyses. BM, BF, CB drafted the manuscript. AV, LD, TH, BC, GP, JM participated in study analyses, manuscript preparation and revised it critically for important intellectual content. All authors reviewed and approved the final version of the manuscript.

\section{Acknowledgments}

This work was supported in part by the HIVACAT program and grants to CB from MTM2008-06747-C02-00 (GG) from the Ministerio de Ciencia y Tecnología, Spain, FIPSE 36-0737-0, The European Community (CUT'HIVAC, EC-FP7-241904), by the Intramural Research Program of the National Cancer Institute, National Institutes of Health (NCI/NIH) (BKF, GNP) and by NIH grant P01Al057005 to JIM. BM was supported by a research fellowship grant from the ISCIII (Rio Hortega, CM08/00020), and is at present time a Joan Rodés investigator from the ISCIII (JR13/00024), Madrid, Spain. CB is ICREA (Institució Catalana de Recerca I Estudis Avançats) Senior Research Professor. The work was further supported by an unrestricted gift by Rafael Punter, Barcelona and the Barcelona HIV Gala 2013. We thank D. Weiss, J. Treece and staff at Bioqual for their support, J. Bear, B. Chowdhury and R.K. Beach for technical support, and T. Jones for editorial assistance.

\section{Author details}

${ }^{1}$ IrsiCaixa AIDS Research Institute - HIVACAT, Hospital Germans Trias i Pujol, Crta Canyet s/n., 08916 Badalona, Barcelona, Spain. 'Lluita contra la Sida' Foundation, Hospital Germans Trias i Pujol, Badalona, Barcelona, Spain. ${ }^{3}$ Universitat de Vic-Universitat Central de Catalunya (UVic-UCC), Vic, Spain. ${ }^{4}$ Human Retrovirus Pathogenesis Section, National Cancer Institute-Frederick, Frederick, MD, USA. ${ }^{5}$ Human Retrovirus Section, National Cancer Institute-Frederick, Frederick, MD, USA. ${ }^{6}$ Inovio Pharmaceuticals Inc, Blue Bell, PA, USA. ${ }^{7}$ HIV Unit, Hospital de la Vall d'Hebrón, Barcelona, Spain. ${ }^{8}$ Centres Penitenciaris BCN, Barcelona, Spain. 'University of Washington, Seattle, WA, USA. ${ }^{10}$ Nuffield Department of Medicine, University of Oxford, The John Radcliffe Hospital, Oxford, UK. ${ }^{11}$ The Jenner Institute, University of Oxford, Oxford, UK. ${ }^{12}$ Universitat Autònoma de Barcelona, Barcelona, Spain.

${ }^{13}$ Institució Catalana de Recerca i Estudis Avançats (ICREA), Barcelona, Spain.

Received: 28 November 2014 Accepted: 13 January 2015

\section{Published online: 15 February 2015}

\section{References}

1. Brander C, Frahm N, Walker BD. The challenges of host and viral diversity in HIV vaccine design. Curr Opin Immunol. 2006;18:430-7.

2. Zuñiga R, Lucchetti A, Galvan P, Sanchez S, Sanchez C, Hernandez A, et al. Relative dominance of Gag p24-specific cytotoxic T lymphocytes is associated with human immunodeficiency virus control. J Virol. 2006;80:3122-5.

3. Frahm N, Kiepiela P, Adams S, Linde CH, Hewitt HS, Sango K, et al. Control of human immunodeficiency virus replication by cytotoxic T lymphocytes targeting subdominant epitopes. Nat Immunol. 2006;7:173-8.

4. Kiepiela P, Ngumbela K, Thobakgale C, Ramduth D, Honeyborne I, Moodley E, et al. CD8+ T-cell responses to different HIV proteins have discordant associations with viral load. Nat Med. 2007;13:46-53.

5. Janes H, Friedrich DP, Krambrink A, Smith RJ, Kallas EG, Horton H, et al. Vaccine-induced gag-specific T cells are associated with reduced viremia after HIV-1 infection. J Infect Dis. 2013;208:1231-9.

6. Ranasinghe S, Flanders M, Cutler S, Soghoian DZ, Ghebremichael M, Davis I, et al. HIV-specific CD4 T cell responses to different viral proteins have discordant associations with viral load and clinical outcome. J Virol. 2012;86:277-83.
7. Ranasinghe S, Cutler S, Davis I, Lu R, Soghoian DZ, Qi Y, et al. Association of HLA-DRB1-restricted CD4 ${ }^{+} \mathrm{T}$ cell responses with HIV immune control. Nat Med. 2013;19:930-3.

8. Sacha JB, Chung C, Rakasz EG, Spencer SP, Jonas AK, Bean AT, et al. Gag-specific CD8+ T lymphocytes recognize infected cells before AIDS-virus integration and viral protein expression. J Immunol. 2007;178:2746-54.

9. Chen DY, Balamurugan A, Ng HL, Cumberland WG, Yang OO. Epitope targeting and viral inoculum are determinants of Nef-mediated immune evasion of HIV-1 from cytotoxic T lymphocytes. Blood. 2012;120:100-11.

10. Borghans JAM, Mølgaard A, de Boer RJ, Keşmir C. HLA alleles associated with slow progression to AIDS truly prefer to present HIV-1 p24. PLoS One. 2007;2:e920.

11. Yang $\mathrm{OO}$, Daar $\mathrm{ES}, \mathrm{Ng} \mathrm{HL}$, Shih $\mathrm{R}$, Jamieson $\mathrm{BD}$. Increasing $\mathrm{CTL}$ targeting of conserved sequences during early HIV-1 infection is correlated to decreasing viremia. AIDS Res Hum Retroviruses. 2011;27:391-8.

12. Schneidewind A, Brockman MA, Yang R, Adam Rl, Li B, Le Gall S, et al. Escape from the dominant HLA-B27-restricted cytotoxic T-lymphocyte response in Gag is associated with a dramatic reduction in human immunodeficiency virus type 1 replication. J Virol. 2007;81:12382-93.

13. Brockman MA, Schneidewind A, Lahaie M, Schmidt A, Miura T, Desouza I, et al. Escape and compensation from early HLA-B57-mediated cytotoxic T-lymphocyte pressure on human immunodeficiency virus type 1 Gag alter capsid interactions with cyclophilin A. J Virol. 2007;81:12608-18.

14. Chopera DR, Wright JK, Brockman MA, Brumme ZL. Immune-mediated attenuation of HIV-1. Future Virol. 2011:6:917-28.

15. Brockman MA, Brumme ZL, Brumme CJ, Miura T, Sela J, Rosato PC, et al. Early selection in Gag by protective HLA alleles contributes to reduced HIV-1 replication capacity that may be largely compensated for in chronic infection. J Virol. 2010;84:11937-49.

16. Troyer RM, McNevin J, Liu Y, Zhang SC, Krizan RW, Abraha A, et al. Variable fitness impact of HIV-1 escape mutations to cytotoxic T lymphocyte (CTL) response. PLoS Pathog. 2009;5:e1000365.

17. Kulkarni V, Rosati M, Valentin A, Ganneru B, Singh AK, Yan J, et al. HIV-1 p24 (gag) derived conserved element DNA vaccine increases the breadth of immune response in mice. PLoS One. 2013;8:e60245.

18. Kulkarni V, Valentin A, Rosati M, Alicea C, Singh AK, Jalah R, et al. Altered response hierarchy and increased T-cell breadth upon HIV-1 conserved element DNA vaccination in Macaques. PLoS One. 2014;9:e86254.

19. Rolland M, Nickle DC, Mullins JI. HIV-1 group M conserved elements vaccine. PLoS Pathog. 2007:3:e157.

20. Dinges $W L$, Richardt J, Friedrich D, Jalbert E, Liu Y, Stevens CE, et al. Virus-specific CD8+ T-cell responses better define HIV disease progression than HLA genotype. J Virol. 2010;84:4461-8.

21. Kunwar P, Hawkins N, Dinges WL, Liu Y, Gabriel EE, Swan DA, et al. Superior control of HIV-1 replication by CD8+ T cells targeting conserved epitopes: implications for HIV vaccine design. PLoS One. 2013;8:e64405.

22. Niu L, Termini JM, Kanagavelu SK, Gupta S, Rolland MM, Kulkarni V, et al. Preclinical evaluation of HIV-1 therapeutic ex vivo dendritic cell vaccines expressing consensus Gag antigens and conserved Gag epitopes. Vaccine. 2011;29:2110-9.

23. Buchbinder SP, Mehrotra DV, Duerr A, Fitzgerald DW, Mogg R, Li D, et al. Efficacy assessment of a cell-mediated immunity HIV-1 vaccine (the Step Study): a double-blind, randomised, placebo-controlled, test-of-concept trial. Lancet. 2008;372:1881-93.

24. Rerks-Ngarm S, Pitisuttithum P, Nitayaphan S, Kaewkungwal J, Chiu J, Paris R, et al. Vaccination with ALVAC and AIDSVAX to prevent HIV-1 infection in Thailand. N Engl J Med. 2009;361:2209-20.

25. Hammer SM, Sobieszczyk ME, Janes H, Karuna ST, Mulligan MJ, Grove D, et al. Efficacy trial of a DNA/rAd5 HIV-1 preventive vaccine. N Engl J Med. 2013;369:2083-92

26. Rolland M, Tovanabutra S, de Camp AC, Frahm N, Gilbert PB, Sanders-Buell E, et al. Genetic impact of vaccination on breakthrough HIV-1 sequences from the STEP trial. Nat Med. 2011;17:366-71.

27. Mothe B, Llano A, Ibarrondo J, Zamarreño J, Schiaulini M, Miranda C, et al. $C T L$ responses of high functional avidity and broad variant cross-reactivity are associated with HIV control. PLoS One. 2012;7:e29717.

28. Mothe B, Llano A, Ibarrondo J, Daniels M, Miranda C, Zamarreño J, et al. Definition of the viral targets of protective HIV-1-specific T cell responses. J Transl Med. 2011;9:208. 
29. Pollard RB, Rockstroh JK, Pantaleo G, Asmuth DM, Peters B, Lazzarin A, et al Safety and efficacy of the peptide-based therapeutic vaccine for HIV-1, Vacc-4x: a phase 2 randomised, double-blind, placebo-controlled trial. Lancet Infect Dis. 2014;14:291-300.

30. Lind A, Brekke K, Sommerfelt M, Holmberg JO, Aass HCD, Baksaas I, et al. Boosters of a therapeutic HIV-1 vaccine induce divergent T cell responses related to regulatory mechanisms. Vaccine. 2013;31:4611-8.

31. Karlsson I, Kløverpris H, Jensen KJ, Stryhn A, Buus S, Karlsson A, et al. Identification of conserved subdominant HIV Type 1 CD8(+) T Cell epitopes restricted within common HLA Supertypes for therapeutic HIV Type 1 vaccines. AIDS Res Hum Retroviruses. 2012;28:1434-43.

32. Fischer W, Perkins S, Theiler J, Bhattacharya T, Yusim K, Funkhouser R, et al. Polyvalent vaccines for optimal coverage of potential T-cell epitopes in global HIV-1 variants. Nat Med. 2007;13:100-6.

33. Barouch $\mathrm{DH}, \mathrm{O}^{\prime}$ Brien $\mathrm{KL}$, Simmons NL, King SL, Abbink P, Maxfield LF, et al. Mosaic HIV-1 vaccines expand the breadth and depth of cellular immune responses in rhesus monkeys. Nat Med. 2010;16:319-23.

34. Nickle DC, Rolland M, Jensen MA, Pond SLK, Deng W, Seligman M, et al. Coping with viral diversity in HIV vaccine design. PLoS Comput Biol. 2007;3:e75.

35. Fischer W, Liao HX, Haynes BF, Letvin NL, Korber B. Coping with viral diversity in HIV vaccine design: a response to Nickle et al. PLoS Comput Biol. 2008;4:e15. author reply e25.

36. Frahm N, Korber BT, Adams CM, Szinger JJ, Draenert R, Addo MM, et al. Consistent cytotoxic-T-lymphocyte targeting of immunodominant regions in human immunodeficiency virus across multiple ethnicities. J Virol. 2004;78:2187-200

37. Nasioulas G, Zolotukhin AS, Tabernero C, Solomin L, Cunningham CP, Pavlakis GN, et al. Elements distinct from human immunodeficiency virus type 1 splice sites are responsible for the Rev dependence of env mRNA J Virol. 1994;68:2986-93.

38. Schneider R, Campbell M, Nasioulas G, Felber BK, Pavlakis GN. Inactivation of the human immunodeficiency virus type 1 inhibitory elements allows Rev-independent expression of Gag and Gag/protease and particle formation. J Virol. 1997;71:4892-903.

39. Schwartz S, Felber BK, Pavlakis GN. Distinct RNA sequences in the gag region of human immunodeficiency virus type 1 decrease RNA stability and inhibit expression in the absence of Rev protein. J Virol. 1992;66:150-9.

40. Kulkarni V, Jalah R, Ganneru B, Bergamaschi C, Alicea C, von Gegerfelt A, et al. Comparison of immune responses generated by optimized DNA vaccination against SIV antigens in mice and macaques. Vaccine. 2011;29:6742-54

41. Jalah R, Rosati M, Ganneru B, Pilkington GR, Valentin A, Kulkarni V, et al. The p40 subunit of interleukin (IL)-12 promotes stabilization and export of the p35 subunit: implications for improved IL-12 cytokine production. J Biol Chem. 2013:288:6763-76.

42. Létourneau S, Im E-J, Mashishi T, Brereton C, Bridgeman A, Yang H, et al. Design and pre-clinical evaluation of a universal HIV-1 vaccine. PLoS One. 2007;2:e984

43. Nkolola JP, Wee EG-T, Im E-J, Jewell CP, Chen N, Xu X-N, et al. Engineering RENTA, a DNA prime-MVA boost HIV vaccine tailored for Eastern and Central Africa. Gene Ther. 2004;11:1068-80.

44. PeptGen Peptide Generator [http://www.hiv.lanl.gov/content/sequence/ PEPTGEN/peptgen.html]

45. Patel V, Jalah R, Kulkarni V, Valentin A, Rosati M, Alicea C, et al. DNA and virus particle vaccination protects against acquisition and confers control of viremia upon heterologous simian immunodeficiency virus challenge. Proc Natl Acad Sci U S A. 2013;110:2975-80

46. Burrows SR, Rossjohn J, McCluskey J. Have we cut ourselves too short in mapping CTL epitopes? Trends Immunol. 2006;27:11-6.

47. Le Gall S, Stamegna P, Walker BD. Portable flanking sequences modulate CTL epitope processing. J Clin Invest. 2007;117:3563-75.

48. Yusim K, Korber BT, Brander C, Barouch DH, de Boer RJ, Haynes BF, et al. HIV Molecular Immunology. Los Alamos, New Mex: Los Alamos Natl Lab Theor Biol Biophys; 2011

49. Brumme ZL, John M, Carlson JM, Brumme CJ, Chan D, Brockman MA, et al HLA-associated immune escape pathways in HIV-1 subtype B Gag, Pol and Nef proteins. PLoS One. 2009;4:e6687.

50. Liu TF, Shafer RW. Web resources for HIV type 1 genotypic-resistance test interpretation. Clin Infect Dis. 2006;42:1608-18.
51. Kuiken C, Foley B, Leitner T, Apetrei C, Hahn BH, Mizrachi I, et al. HIV Sequence Compendium. LA-UR: Theor Biol Biophys Group, Los Alamos Natl Lab NM; 2011. p. 11-11440

52. Sidney J, Peters B, Frahm N, Brander C, Sette A. HLA class I supertypes: a revised and updated classification. BMC Immunol. 2008;9:1.

53. Kaufmann DE, Bailey PM, Sidney J, Wagner B, Norris PJ, Johnston MN, et al. Comprehensive analysis of human immunodeficiency virus type 1-specific CD4 responses reveals marked immunodominance of gag and nef and the presence of broadly recognized peptides. J Virol. 2004;78:4463-77.

54. Zhang SC, Martin E, Shimada M, Godfrey SB, Fricke J, Locastro S, et al. Aminopeptidase substrate preference affects HIV epitope presentation and predicts immune escape patterns in HIV-infected individuals. J Immunol. 2012;188:5924-34.

55. Llano A, Williams A, Olvera A, Silvia-Arrieta S, Brander C. Best-Characterized HIV-1 CTL Epitopes: The 2013 Update. Los Alamos, New Mex: HIV Mol Immunol Los Alamos Natl Lab Theor Biol Biophys; 2013. p. 3-25.

56. Rihn SJ, Wilson SJ, Loman NJ, Alim M, Bakker SE, Bhella D, et al. Extreme genetic fragility of the HIV-1 capsid. PLoS Pathog. 2013;9:e1003461.

57. Carrington M, O'Brien SJ. The influence of HLA genotype on AIDS. Annu Rev Med. 2003;54:535-51

58. O'Brien SJ, Gao X, Carrington M. HLA and AIDS: a cautionary tale. Trends Mol Med. 2001;7:379-81.

59. Rosati M, von Gegerfelt A, Roth $\mathrm{P}$, Alicea C, Valentin A, Robert-Guroff M, et al. DNA vaccines expressing different forms of simian immunodeficiency virus antigens decrease viremia upon SIVmac251 challenge. J Virol. 2005;79:8480-92.

60. Dorrell L, Yang H, Ondondo B, Dong T, Gleria K, Suttill A, et al. Expansion and diversification of virus-specific $T$ cells following immunization of Human Immunodeficiency Virus Type 1 ( HIV-1) -infected individuals with a recombinant modified vaccinia virus ankara/HIV-1 gag vaccine. J Virol. 2006;80:4705-16

61. Hanke T, Goonetilleke N, McMichael AJ, Dorrell L. Clinical experience with plasmid DNA- and modified vaccinia virus Ankara-vectored human immunodeficiency virus type 1 clade A vaccine focusing on T-cell induction. J Gen Virol. 2007:88(Pt 1):1-12.

62. Loffredo JT, Sidney J, Bean AT, Beal DR, Bardet W, Wahl A, et al. Two MHC class I molecules associated with elite control of immunodeficiency virus replication, Mamu-B*08 and HLA-B*2705, bind peptides with sequence similarity. J Immunol. 2009;182:7763-75.

63. Patel V, Valentin A, Kulkarni V, Rosati M, Bergamaschi C, Jalah R, et al. Long-lasting humoral and cellular immune responses and mucosal dissemination after intramuscular DNA immunization. Vaccine. 2010;28:4827-36.

64. Betts MR, Nason MC, West SM, De Rosa SC, Migueles SA, Abraham J, et al. HIV nonprogressors preferentially maintain highly functional HIV-specific CD8+ T cells. Blood. 2006;107:4781-9.

65. Martins MA, Wilson NA, Piaskowski SM, Weisgrau KL, Furlott JR, Bonaldo MC, et al. Vaccination with gag, vif, and nef gene fragments affords partial control of viral replication after mucosal challenge with SIVmac239. J Virol. 2014:88:7493-516.

66. Mudd PA, Martins MA, Ericsen AJ, Tully DC, Power KA, Bean AT, et al. Vaccine-induced CD8+ T cells control AIDS virus replication. Nature. 2012;491:129-33.

67. Rolland M, Manocheewa S, Swain JV, Lanxon-Cookson EC, Kim M, Westfall DH, et al. HIV-1 conserved-element vaccines: relationship between sequence conservation and replicative capacity. J Virol. 2013;87:5461-7.

68. Manocheewa S, Swain JV, Lanxon-Cookson E, Rolland M, Mullins Jl. Fitness costs of mutations at the HIV-1 capsid hexamerization interface. PLoS One. 2013:8:e66065.

69. Hancock G, Yang $H$, Yorke E, Wainwright E, Bourne V, Frisbee A, et al. Identification of effective subdominant anti-HIV-1 CD8+ T cells within entire post-infection and post-vaccination immune responses. PLoS Pathog 2015 in press.

70. Yang H, Wu H, Hancock G, Clutton G, Sande N, Xu X, et al. Antiviral inhibitory capacity of CD8+ T cells predicts the rate of CD4+ T-cell decline in HIV-1 infection. J Infect Dis. 2012;206:552-61.

71. Shan L, Deng K, Shroff NS, Durand CM, Rabi SA, Yang H-C, et al. Stimulation of HIV-1-specific cytolytic T lymphocytes facilitates elimination of latent viral reservoir after virus reactivation. Immunity. 2012;36:491-501.

72. Deng K, Pertea M, Rongvaux A, Wang L, Durand CM, Ghiaur G, et al. Broad $C T L$ response is required to clear latent HIV-1 due to dominance of escape mutations. Nature. 2015;517:381-5. 
73. Frahm N, Kaufmann DE, Yusim K, Muldoon M, Kesmir C, Linde $\mathrm{CH}$, et al. Increased sequence diversity coverage improves detection of HIV-specific T cell responses. J Immunol. 2007;179:6638-50.

74. Rolland M, Frahm N, Nickle DC, Jojic N, Deng W, Allen TM, et al. Increased breadth and depth of cytotoxic T lymphocytes responses against HIV-1-B Nef by inclusion of epitope variant sequences. PLoS One. 2011;6:e17969.

75. García F, Bernaldo de Quirós JCL, Gómez CE, Perdiguero B, Nájera JL, Jiménez $V$, et al. Safety and immunogenicity of a modified pox vector-based HIV/AIDS vaccine candidate expressing Env, Gag, Pol and Nef proteins of HIV-1 subtype B (MVA-B) in healthy HIV-1-uninfected volunteers: A phase I clinical trial (RISVAC02). Vaccine. 2011;29:8309-16.

76. Chen J, Frey G, Peng H, Rits-Volloch S, Garrity J, Seaman MS, et al. Mechanism of HIV-1 neutralization by antibodies targeting a membrane-proximal region of gp41. J Virol. 2014;88:1249-58.

77. Hanke T, McMichael AJ. HIV-1: from escapism to conservatism. Eur J Immunol. 2011;41:3390-3.

78. Tubiana R, Carcelain G, Vray M, Gourlain K, Dalban C, Chermak A, et al. Therapeutic immunization with a human immunodeficiency virus (HIV) type 1-recombinant canarypox vaccine in chronically HIV-infected patients: The Vacciter Study (ANRS 094). Vaccine. 2005:23:4292-301.

79. Autran B, Murphy RL, Costagliola D, Tubiana R, Clotet B, Gatell J, et al. Greater viral rebound and reduced time to resume antiretroviral therapy after therapeutic immunization with the ALVAC-HIV vaccine (VCP1452) AIDS. 2008:22:1313-22.

80. Casazza JP, Bowman KA, Adzaku S, Smith EC, Enama ME, Bailer RT, et al. Therapeutic vaccination expands and improves the function of the HIV-specific memory T-cell repertoire. J Infect Dis. 2013;207:1829-40.

81. Schooley RT, Spritzler J, Wang H, Lederman MM, Havlir D, Kuritzkes DR, et al AIDS clinical trials group 5197: a placebo-controlled trial of immunization of HIV-1-infected persons with a replication-deficient adenovirus type 5 vaccine expressing the HIV-1 core protein. J Infect Dis. 2010;202:705-16.

82. Hansen SG, Piatak M, Ventura AB, Hughes CM, Gilbride RM, Ford JC, et al Immune clearance of highly pathogenic SIV infection. Nature. 2013;502:100-4

83. Hansen SG, Sacha JB, Hughes CM, Ford JC, Burwitz BJ, Scholz I, et al. Cytomegalovirus vectors violate CD8+ T cell epitope recognition paradigms. Science. 2013;340:1237874.

84. Hansen SG, Ford JC, Lewis MS, Ventura AB, Hughes CM, Coyne-Johnson L, et al. Profound early control of highly pathogenic SIV by an effector memory T-cell vaccine. Nature. 2011:473:523-7.

85. Koopman G, Beenhakker N, Nieuwenhuis I, Doxiadis G, Mooij P, Drijfhout JW, et al. DNA/long peptide vaccination against conserved regions of SIV induces partial protection against SIVmac251 challenge. AIDS. 2013;27:2841-51.

\section{Submit your next manuscript to BioMed Central and take full advantage of:}

- Convenient online submission

- Thorough peer review

- No space constraints or color figure charges

- Immediate publication on acceptance

- Inclusion in PubMed, CAS, Scopus and Google Scholar

- Research which is freely available for redistribution 